MEI, II, Vol. 4, nº 6, pág. 55

\title{
El acceso abierto en las universidades españolas: estado de la cuestión y propuestas de mejora \\ MEI
}

II, vol. 4

$n^{\circ} 6$
Mabela Casal Reyes', Maria Dolores Borgoños Martinez², Anna

Casaldáliga $^{3}$, Javier Gómez Castaño ${ }^{4}$, Concepción Guijarro ${ }^{5}$, Eva Ortiz

Uceta $^{6}$, Almudena Pascual del Pobil Valdenebro ${ }^{7}$, Fernando Rodríguez

Junco $^{8}$, Isabel Terroba Pascual 9

1Biblioteca Universitaria de Santiago de Compostela; 2 Universidad de Murcia; 3 Universitat Pompeu Fabra; 4

Universidad de Alicante; 5 Universidad Pública de Navarra; 6 Universidad Carlos III de Madrid; 7 Universidad

de Sevilla; 8 Universidad de La Laguna; 9 Universidad de La Rioja

\section{Resumen}

Este trabajo analiza la situación actual de los repositorios institucionales en las universidades españolas, desde el punto de vista de sus contenidos, las políticas de depósito y acceso a la investigación y el estado de cumplimiento de las políticas nacionales referentes al archivo en los repositorios institucionales en la actualidad. Para ello se ha partido de los resultados de una encuesta elaborada en el marco del III Plan estratégico REBIUN 2020 (2011), concretamente en la línea estratégica 2 dedicada a "Dar soporte a la docencia, aprendizaje e investigación y gestión”. A partir del análisis obtenido, se establecen unas recomendaciones para favorecer el desarrollo de los repositorios y conseguir incrementar el impacto y visibilidad de las universidades españolas.

\section{Palabras clave}

Acceso abierto, Universidades, España, Repositorios, Mandatos.

Open access in Spanish universities: state of the art and proposals for improvement

\section{Abstract}

This paper analyzes the current situation of institutional repositories in Spanish universities, from the point of view of content, deposit policies and access to research and the status of implementation of national policies relating to the file in institutional repositories today. To do this we have started from the results of a survey conducted under the Strategic Plan III REBIUN 2020 (2011), specifically in the strategic line two dedicated "To support teaching, learning and research and management." Obtained from the analysis, we suggest some recommendations for promoting the development of repositories and get increase the impact and visibility of Spanish universities.

Keywords

Open Access, Universities, Spain, Repositories, Mandates. 


\section{1-Introducción}

Este trabajo tiene su origen en una de las acciones derivadas del vigente III Plan estratégico REBIUN 2020 (2011), concretamente en la línea estratégica 2 dedicada a "Dar soporte a la docencia, aprendizaje e investigación y gestión", donde se encuentra el siguiente objetivo:

Objetivo 4. Promover mandatos y políticas institucionales de acceso abierto a la producción científica de cada universidad para incrementar la visibili dad y el impacto de la universidad.

Para alcanzar su cumplimiento se fija como objetivo operativo en el año 2012 la elaboración de un Estado de la cuestión sobre el acceso abierto en las universidades españolas, a partir del análisis de una encuesta enviada en octubre de ese mismo año a los miembros de REBIUN.

La encuesta se envió a 74 universidades recibiéndose 65 contestaciones, lo que supone una participación del $88 \%$. A partir del análisis de esa encuesta se han obtenido una serie de conclusiones que dibujan el panorama actual de los repositorios institucionales en la universidad española y permiten exponer una serie de recomendaciones para favorecer su desarrollo y potenciar su impacto.

Este análisis no sería posible sin enmarcarlo dentro del contexto del movimiento Open Access que ha dado lugar a la publicación de diferentes declaraciones y ha generado en España un marco legal y un conjunto de políticas institucionales.

\subsection{Una nueva forma de comunicación científica}

El movimiento de acceso abierto (Open Access) a la ciencia es una interesante contribución a la investigación y la docencia en el contexto de la sociedad de la información y, por tanto, a la difusión de la ciencia. Tomando la definición de la Budapest Open Access Initiative (BOAI, 2002), por acceso abierto a la literatura científica erudita entendemos "su disponibilidad gratuita en Internet para que cualquier usuario la pueda leer, descargar, copiar, distribuir o imprimir, con la posibilidad de buscar o enlazar al tex to completo del artículo [...] utilizarlo para cualquier otro propósito legal, sin otras barreras financieras, legales o técnicas distintas de la fundamental de acceder a Internet. El único límite a la reproducción y distribución de los artículos publicados, y la única función del copyright en este marco no puede ser otra que garantizar a los autores el control sobre la integridad de su trabajo y el derecho a ser reconocidos y citados".

Desde sus inicios amparados en el OSI, Open Society Institutel, hasta la actualidad, el movimiento Open Access ha ido avanzando de la mano de diversas iniciativas y declaraciones. La germinal Declaración de Budapest (BOAI, 2002) aportó a la comunidad investigadora un nuevo poder, ya que facilitaba el uso de la literatura científica relevante $\mathrm{y}$ daba a los autores $\mathrm{y}$ a sus trabajos nueva visibilidad, eliminando las barreras del precio. 
Lo que hoy en día conocemos por acceso abierto despegó en 2001, con una carta que algunos prestigiosos investigadores dirigieron a sus colegas pidiéndoles que se negaran a publicar en revistas en las que no les concedieran el derecho a usar libremente sus artículos, al menos, en el plazo de 6 meses después de su publicación. El movimiento se consolidó y se conoce actualmente como Public Library of Science $e^{2}$.

Tras Budapest llegó en junio de 2003 la Declaración de Bethesda (Bethesda Statement on Open Access Publishing, 2003) y en octubre de ese mismo año la Declaración de Berlín (Berlin Declaration on Open Access to Knowledge in the Sciences and Humanities, 2003), sin duda uno de los hitos del acceso abierto y, por ello, suscrita también por numerosas universidades ${ }^{3}$.

\subsection{Terminología para situar los repositorios institucionales de universidades}

El acceso abierto contempla la existencia de Portales (que reúnen la información ubicada en distintos depósitos o repositorios) y de Repositorios de diferente tipología (en los que están almacenados los documentos). Las universidades tienen, conforme a ésta definición, repositorios institucionales (aquellos que contienen documentación almacenada que genera su universidad, fundamentalmente su propia producción científica). De este modo las diferentes universidades adquieren visibilidad y muestran su excelencia en calidad docente e investigación, mejorando así su posicionamiento en rankings internacionales.

La publicación en repositorios institucionales o temáticos constituye la denominada "ruta verde" hacia el acceso abierto". El documento se publica vía autoarchivo o archivo delegado, después de haber sido publicado el artículo en una revista tradicional. Actualmente la mayoría de editoriales permiten depositar una reproducción de sus artículos o los post-prints (versión aceptada de la publicación que incluye los comentarios de la revisión) en los repositorios pasado un período de embargo.

En este contexto podemos definir un repositorio institucional universitario como el lugar donde se organizan, preservan y se difunden a través de Internet, en acceso abierto y gratuito, contenidos digitales producidos por una institución, en múltiples formatos, de manera permanente y asegurando su preservación futura.

\subsection{Iniciativas europeas relacionadas con el acceso abierto}

Es importante reseñar una serie de iniciativas europeas relacionadas con el acceso abierto:

- 2007. El Consejo de Investigación Europeo (ERC) publicó unas directrices propias sobre el acceso abierto (European Research Council, 2007), en las que requiere que todas las publicaciones de proyectos financiados por el ERC revisadas por pares sean depositadas en un repositorio de investigación (temático o institucional) y que estén en acceso abierto en un plazo máximo de 6 meses. 
- 26 de marzo 2008. La Asociación Universitaria Europea (EUA) aprobó en asamblea plenaria celebrada en Barcelona, unas Recomendaciones (EUA, 2008) dirigidas a las universidades con respecto a la creación de repositorios institucionales y desarrollo de políticas para la promoción del acceso abierto.

- VI (2002-2006) y VII (2007-2013) Programa marco I+D de la Unión Europea

- En agosto de 2008 se inició el programa Open Access pilot in FP7 (European Commission, 2008)

- En diciembre de 2009 se inició el proyecto Open Access infrastructure for Research in Europe (OpenAIRE, 2009)

- Iniciativa Horizon 2020 de la Comisión (Comisión Europea, 2012)5.

\subsection{La Situación en España}

Por lo que se refiere al ámbito universitario español hemos de mencionar la declaración de la CRUE / REBIUN (REBIUN, 2004) en apoyo del modelo de acceso electrónico abierto que insta a:

- los autores (especialmente a aquellos que desarrollan proyectos financiados con fondos públicos) a dar prioridad, al enviar sus trabajos para su publicación, a las publicaciones que siguen el modelo de acceso electrónico abierto y en ningún caso, ceder totalmente sus derechos de autor, de modo que puedan depositar copia de sus trabajos en repositorios institucionales de acceso electrónico abierto.

- las instituciones académicas y científicas a crear y mantener repositorios institucionales de acceso electrónico abierto donde se depositen copias de los trabajos científicos producidos por sus profesores e investigadores (artículos, revistas, tesis, informes, etc.) y, en caso de no ser posible el punto anterior, promover el envío de esos trabajos a repositorios de carácter suprainstitucional. Así mismo deben fomentar la publicación de los trabajos de profesores e investigadores en aquellas publicaciones que siguen el modelo de acceso electrónico abierto.

- las autoridades políticas con responsabilidad en el ámbito científico, educativo o cultural a financiar la creación de repositorios institucionales o suprainstitucionales y promover y colaborar en proyectos que contribuyan a la creación y desarrollo de publicaciones de acceso electrónico abierto, o de preservación a largo plazo de la producción científica, educativa y cultural en formato digital libremente accesible".

- Junto a las declaraciones es importante no perder de vista el marco legal en España. Dos son los textos normativos que hay que tener en cuenta:

- Real decreto 99/2011, de 28 de enero, por el que se regulan las enseñanzas oficiales de doctorado (BOE 10 de febrero de 2011). Debemos prestar atención a los artículos 14. 5 y 14. 6. relativos a la obligatoriedad de depositar en acceso abierto las tesis doctorales aprobadas (con alguna excepcionalidad establecida en el 14.6 y en la Disposición transitoria primera $)^{6}$. Por tanto, la obligación de la publicación de la tesis en un repositorio institucional es aplicable desde febrero 2012. 
- Ley 14/2o11, de 1 de junio, de la Ciencia, la Tecnología y la Innovación (BOE 2 de junio de 2011). En este caso son de especial interés los Preámbulos I y VI y el Artículo $37^{7}$.

Esto quiere decir que estamos ante un marco reglamentario de aplicación en universidades públicas españolas para la publicación en acceso abierto. Pero además cada universidad pública debe aplicar políticas específicas e indicar en sus normativas de trabajos fin de máster (TFM), trabajos fin de grado (TFG) la obligación / recomendación de publicar en su repositorio institucional en acceso abierto, los resultados relacionados con los estudios oficiales de máster y doctorado.

Las políticas institucionales de cada universidad, aprobadas en Consejo de Gobierno, con el claro propósito de promover la difusión de la ciencia que producen en acceso abierto, deben comenzar por una declaración de intenciones en la que se recomiende / obligue a depositar publicaciones de investigación llevadas a cabo en la universidad; publicaciones académicas (material docente, etc.) y objetos de aprendizaje (exámenes, ejercicios, etc.); se obligue a depositar a los doctorandos una copia electrónica de la tesis leída y se obligue / recomiende depositar a los estudiantes trabajos o proyectos de fin de máster, grado o carrera. En dichas políticas y normativas de desarrollo se puede limitar el tiempo en el que debe hacerse el archivo de dichos documentos, se debe velar por el respeto a las políticas de propiedad intelectual de las editoriales, trabajar por la integridad de los datos introducidos por los autores, apostar por incrementar la visibilidad e interoperabilidad de la producción científica incorporando su repositorio en buscadores, portales, directorios, etc.

\section{Panorama de los repositorios institucionales en las universidades españolas}

En estudios anteriores (Melero, 2008a; Melero et al, 2009; Abadal et al, 2010, 2013) se ha recogido la evolución de los repositorios institucionales y el acceso abierto en España. Así mismo, existen portales nacionales, como BuscaRepositorios (gestionado por el Grupo de investigación "Acceso abierto a la ciencia"), e internacionales, como $O p e n D O A R^{9}$ y $R O A R^{10}$, que ofrecen una recopilación de la mayor parte de los repositorios existentes a nivel nacional e internacional.

En este artículo nos centraremos en la situación actual de los repositorios institucionales en las universidades españolas, desde el punto de vista de sus contenidos, las políticas de depósito y acceso a la investigación y el estado de cumplimiento de las políticas nacionales referentes al archivo en los repositorios institucionales en la actualidad. Finalmente se establecen unas recomendaciones para favorecer el desarrollo de los repositorios y conseguir incrementar el impacto y visibilidad de las universidades españolas.

Partiendo de la encuesta enviada a las universidades españolas pertenecientes a REBIUN podemos obtener una serie de datos relativos a la situación actual de los repositorios institucionales en estos centros. 
De las 65 universidades que contestaron a la encuesta, 52 afirmaban tener repositorio institucional, 8 no disponían de repositorio pero tenían prevista su creación y 5 no tenían repositorio y desconocían si se crearía en un futuro. Las 5 universidades que no tenían repositorio y tampoco tenían prevista su creación eñalaban que tampoco depositan documentos en otros repositorios.

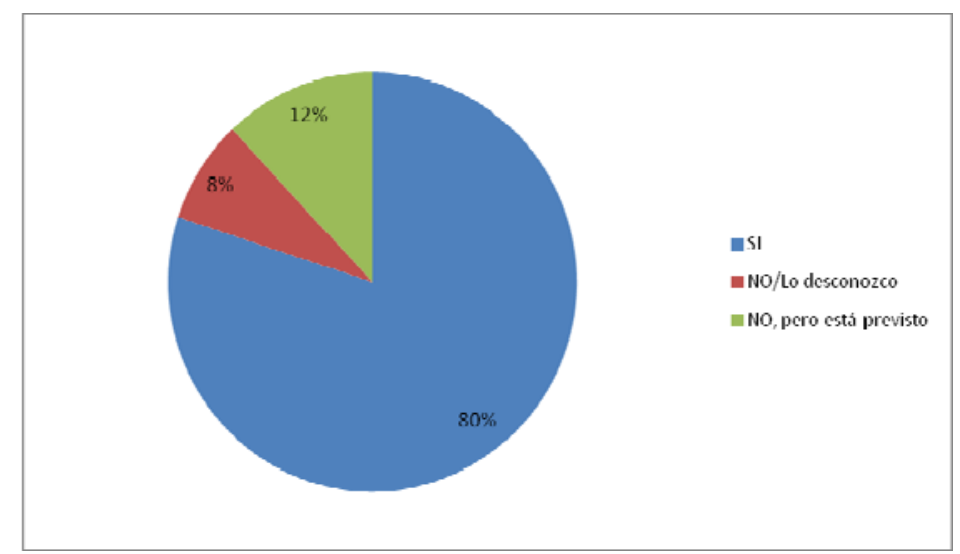

Fig. 1. Instituciones con repositorios institucionales

De las 52 instituciones que afirmaban tener repositorio institucional, tan solo 2 no disponían de repositorio propio sino que empleaban uno compartido.

De las 8 instituciones que no disponían de repositorio pero tenían prevista su creación, 3 universidades ya habían asignado un nombre para el mismo y tenían prevista su puesta en marcha en 2012.

En cuanto a la fecha de creación de los repositorios, el más antiguo es del año 2000, siendo constante la creación de los mismos a partir del año 2006.

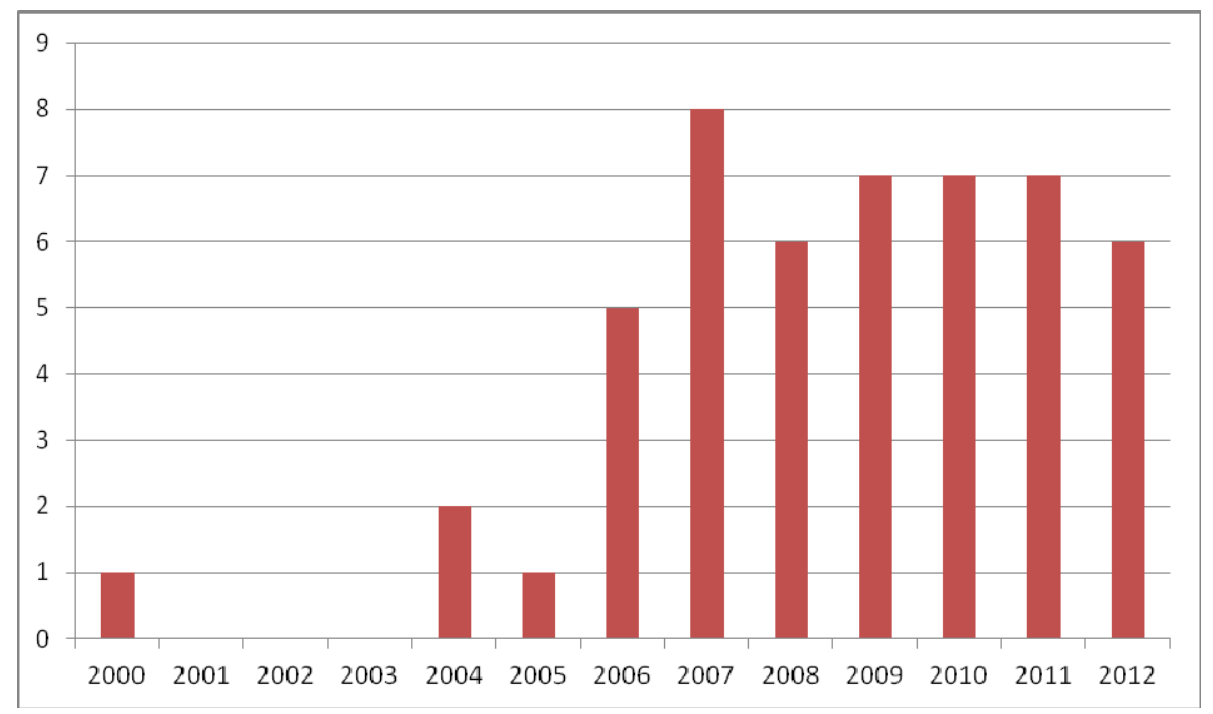

Fig. 2. Número de repositorios institucionales creados por año 
Respecto al número de documentos depositados en los repositorios podemos indicar que en general el volumen es escaso. A este respecto debemos indicar que sólo el $21 \%$ de los repositorios alberga más de 10.000 registros.

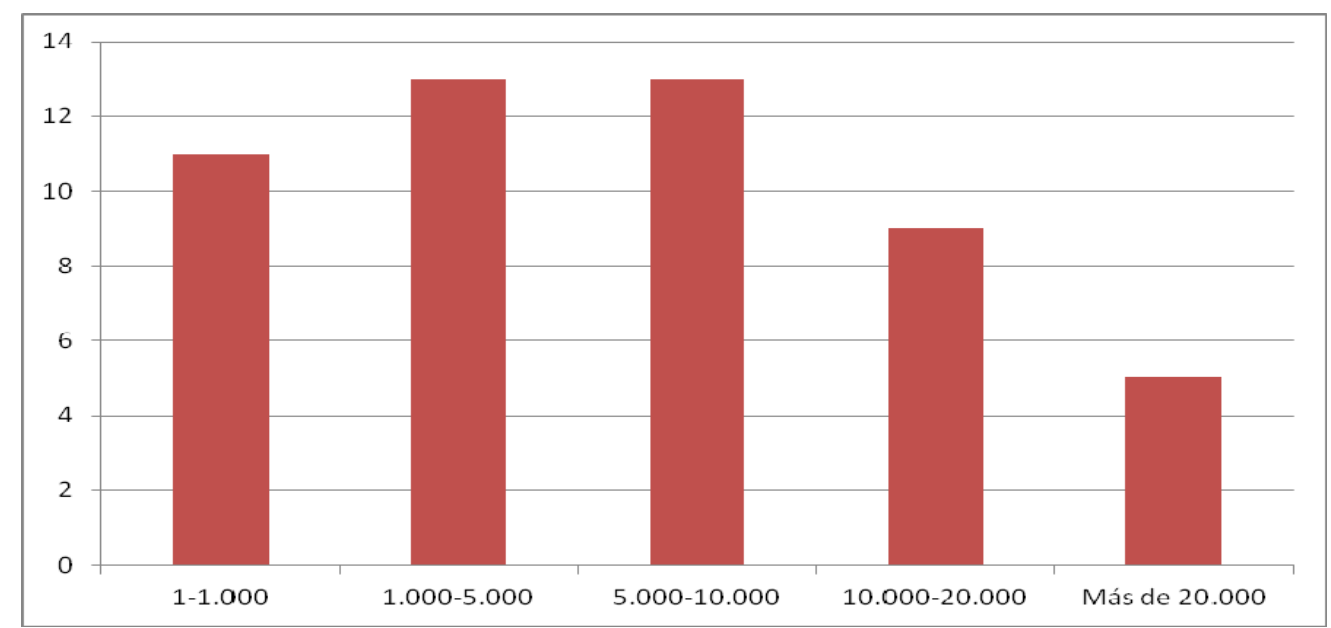

Fig. 3. Repositorios institucionales por número de documentos

Hasta la fecha de realización de la encuesta se señala la existencia de un total de 482.126 documentos depositados en repositorios universitarios españoles.

En cuanto al software utilizado para la implementación del repositorio, las universidades españolas han optado mayoritariamente por el uso de software libre y, concretamente, por DSpace.

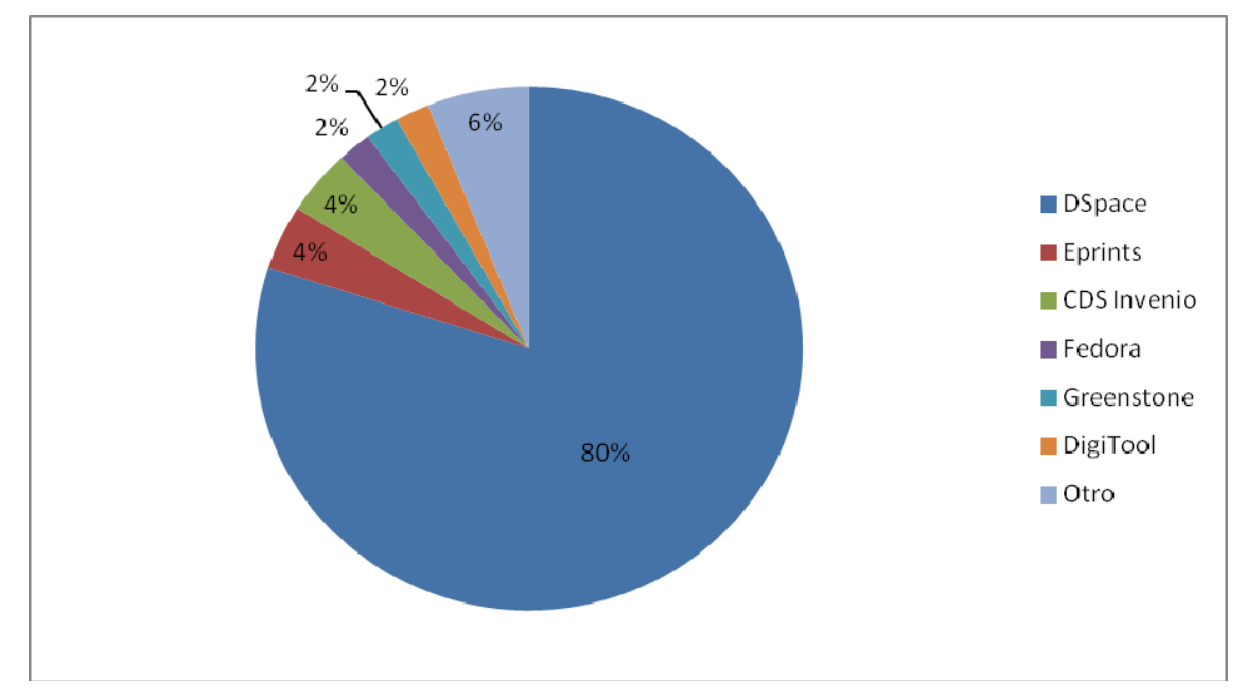

Fig. 4. Software de los repositorios institucionales de universidades españolas

\section{Contenido de los repositorios institucionales de universidades españolas}




\subsection{Tipología documental existente}

De los resultados de la encuesta se desprende que la tipología documental de los archivos que albergan actualmente los repositorios universitarios se puede definir como heterogénea, aunque predomina el depósito de artículos de revista, tesis doctorales y otros trabajos de investigación. Este resultado era previsible, ya que los artículos son el medio de difusión más apreciado en el mundo de la ciencia al estar las revistas (journals) actualizando continuamente resultados de investigación, hecho que les hace ser material imprescindible. El resultado general lo podemos visualizar en el esquema siguiente, en el que se aprecia la diversidad existente.

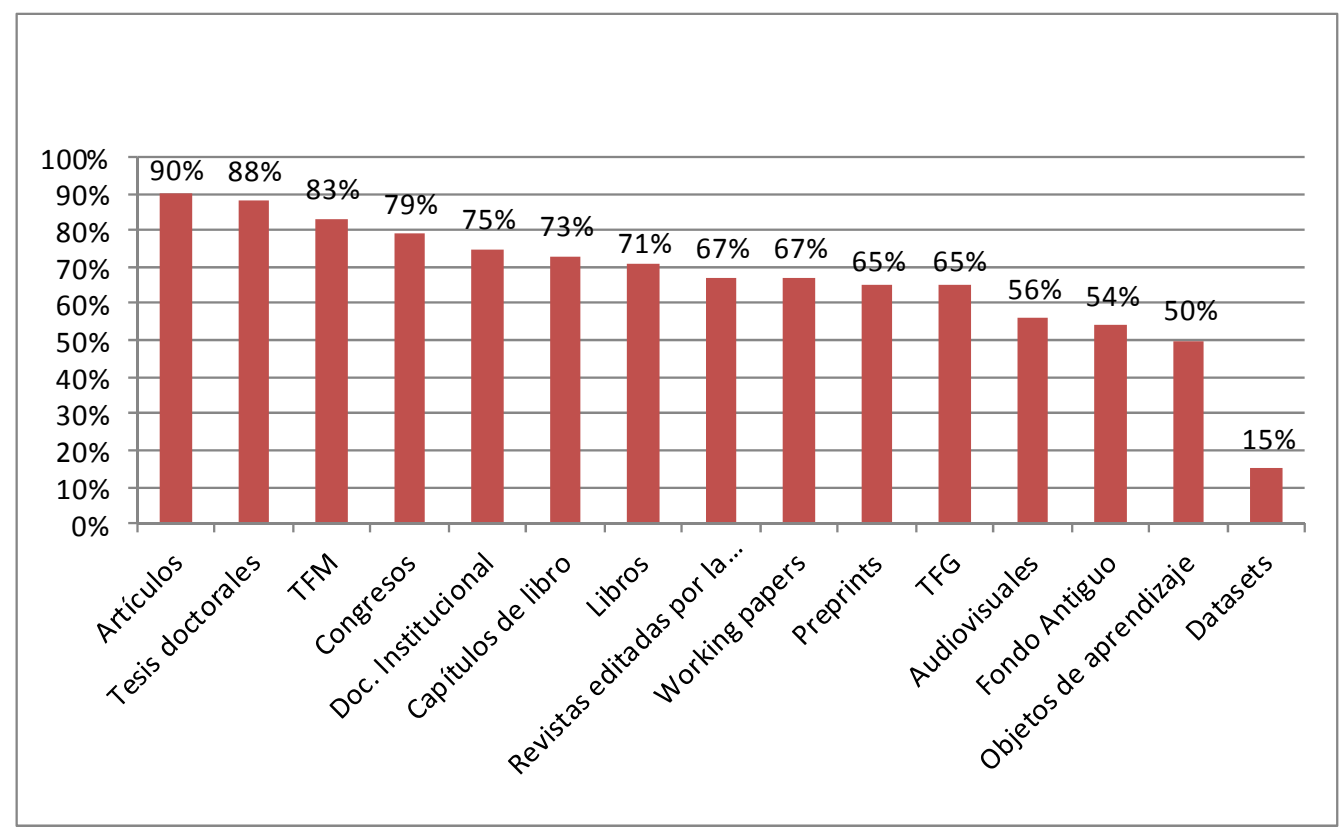

Fig. 5. Tipologías documentales en repositorios institucionales de universidades españolas

\section{2-Quién introduce documentos en los repositorios institucionales}

Los investigadores pueden publicar su producción científica en acceso abierto a través de dos vías, denominadas "rutas":

- "Ruta dorada": publicación de sus trabajos en revistas de acceso abierto.

- "Ruta verde": publicación en repositorios institucionales o temáticos. El documento se publica vía autoarchivo o archivo delegado, después de haber sido publicado el artículo en una revista tradicional. Actualmente la mayoría de editoriales permiten depositar una reproducción de sus artículos o los post-prints en los repositorios, pasado un período de embargo.

El tipo de repositorio que nos ocupa (institucional-ruta verde) puede ser 
incrementado tanto por profesionales en documentación como por los propios usuarios, para lo cual es necesario distinguir entre autoarchivo, archivo delegado y archivo mixto:

- Autoarchivo: el propio autor introduce el documento.

- Archivo delegado: los profesionales en documentación introducen los documentos. En la mayor parte de las universidades es el servicio de biblioteca quien se encarga de dotar de contenidos al repositorio.

- Archivo Mixto: el autor o el profesional en documentación introducen documentos. En la actualidad, el método que más se utiliza es el de archivo mixto, aunque será conveniente estimular más a los usuarios para que el autoarchivo crezca.

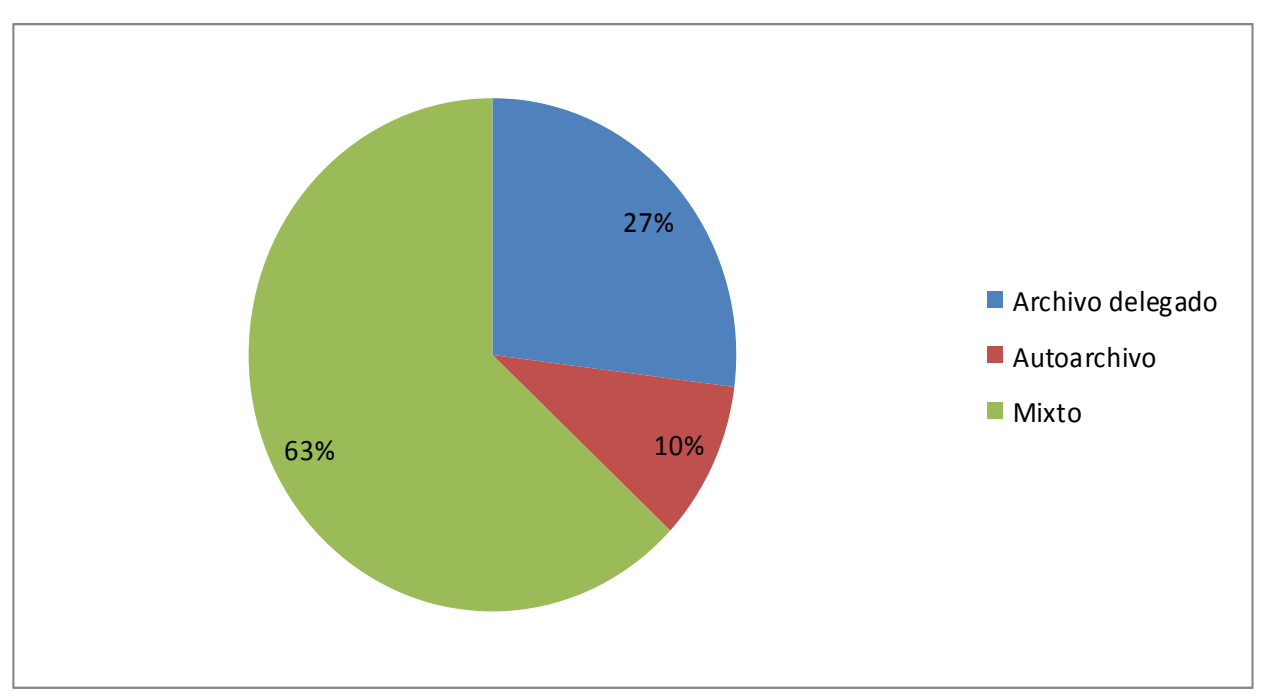

Fig. 6. Cómo se articula el depósito en las instituciones

\subsection{Excepciones para el depósito}

Como un repositorio está compuesto por todos los documentos autorizados que una institución crea conveniente introducir en él, es necesario valorar si algunas de ellas ponen excepciones para publicar o no un tipo de documento determinado, y comprobamos que, aunque con escasa diferencia, la mayoría no tiene excepcionalidad para publicar en él, lo cual supone que en el $54 \%$ se puede introducir cualquier tipo de documento. 


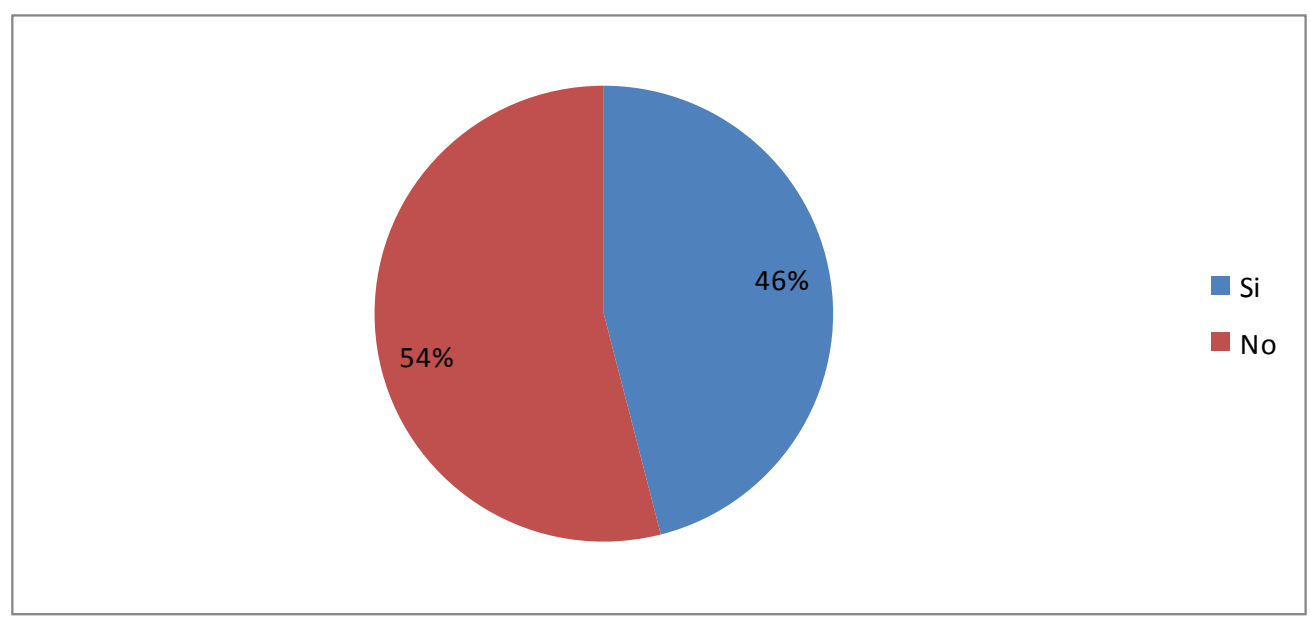

Fig.7. ¿Existen excepciones para depositar documentos?

Las excepciones al depósito se acogen a acuerdos de confidencialidad con empresas, a la existencia de contratos y/o compromisos editoriales y, en el caso de Trabajos Fin de Carrera o Fin de Máster, a la calificación obtenida y/o a la valoración de los tutores de dichos trabajos.

Publicar en repositorios también está protegido, ya que existen las licencias Creative Commons (4 tipos de licencias, combinables hasta 6, a elegir por el sujeto que introduce el documento), de validez internacional. A ellas se suma en ocasiones otro tipo de licencia denominada "institucional", que es la que obliga a aceptar una determinada institución para publicar en su repositorio y de ese modo evitar posteriores problemas legales.

Según datos de la encuesta realizada, el 92 \% de las instituciones utiliza algún tipo de licencia para proteger los documentos contenidos en sus repositorios, siendo las licencias Creative Commons las más utilizadas en un 91,6\% de los casos.

\subsection{Embargo temporal}

El embargo es el periodo de tiempo que transcurre desde la edición de un número hasta que se puede consultar electrónicamente el texto completo en plataformas ajenas a las del propio editor. Cada repositorio define también su propia normativa que delimita cuándo una obra puede entrar a formar parte de él.

La mayoría de instituciones no tienen establecido actualmente ningún tipo de embargo para publicar, pero aquellas que sí lo tienen (46\%) lo distinguen por periodo de tiempo (siendo el mínimo entre 6 y 12 meses) o por tipo de material que se deposita, predominantemente tesis y artículos de revista. 


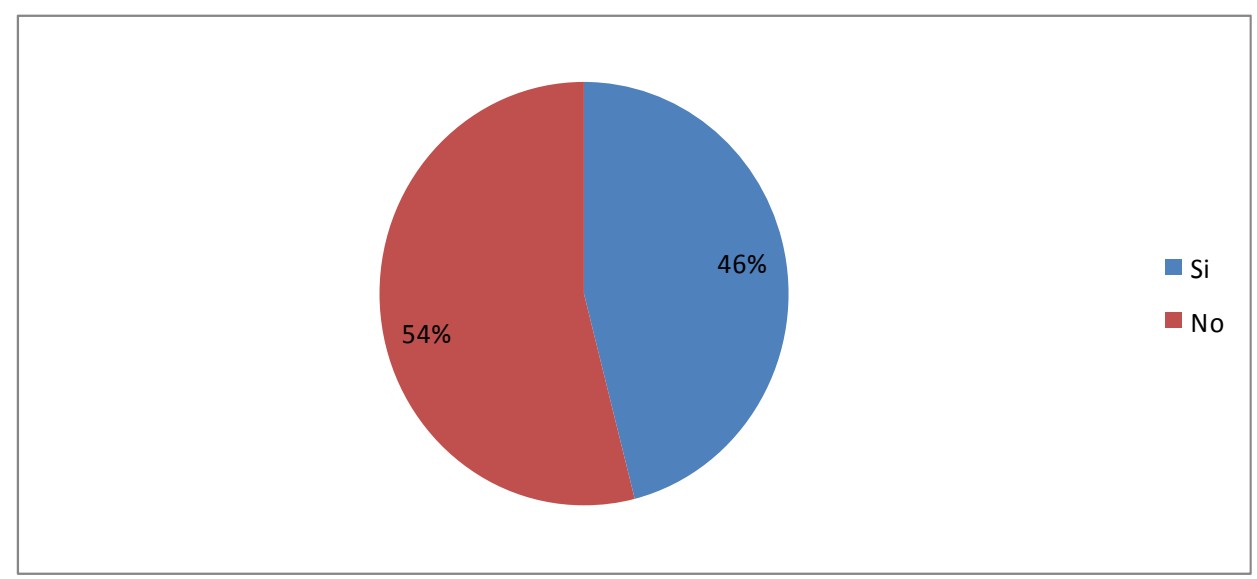

Fig. 8. Embargo temporal

\section{Políticas de depósito y acceso a la investigación}

\subsection{Declaración de Berlín}

Un posible medio para comprobar si existe un compromiso de parte de las instituciones hacia el Open Access es analizar cuántas de las universidades pertenecientes a REBIUN han firmado la Declaración de Berlín.

Según la encuesta, 25 de las 65 instituciones que respondieron a esta pregunta la habían firmado. Este número ha aumentado desde la realización de la misma ya que hemos comprobado que 5 universidades más se han adherido ${ }^{11}$. Estas 5 universidades se engloban dentro del $23 \%$ que respondieron que no habían firmado pero que estaba previsto.

Es decir, en total 31 instituciones de 65 , lo que supone un $47.6 \%$. En la gran mayoría de los casos (27 instituciones) fue el Rector quien firmó. En algún caso lo hizo el Consejo de Gobierno o el Vicerrector de Biblioteca.

Si analizamos los años de la firma, destaca el elevado número de adhesiones que se realizaron en 2006 (año de la firma de las universidades públicas madrileñas y la UNED pertenecientes al Consorcio Madroño). Se aprecia un ligero repunte a partir del año 2011.

\subsection{Políticas sobre Open Access}

Gran parte del objetivo de la encuesta era obtener información acerca de las políticas institucionales sobre Open Access.

Sin duda, este es un tema de gran importancia. El movimiento Open Access está presente en la comunidad científica internacional desde hace ya tiempo, pero ello no quiere decir que todos los investigadores conozcan en profundidad este nuevo paradigma de comunicación científica, que aboga por una amplia difusión del 
conocimiento y un retorno de la inversión pública. Es un modelo complementario al modelo tradicional comercial de publicación científica. Los investigadores de la universidad realizan las investigaciones cuyos resultados se publican en revistas comerciales a las que generalmente se cede en exclusiva los derechos patrimoniales de autor. Los costes que han abonar las bibliotecas de las universidades por las suscripciones de dichas revistas son muy onerosos.

La existencia de una política institucional de apoyo al acceso abierto es un firme respaldo al movimiento. La universidad se posiciona como garante del acceso universal gratuito a la producción científica e intelectual de sus investigadores, repercutiendo este acceso al conocimiento global de la sociedad.

Las políticas institucionales también son un medio para establecer una declaración de intenciones, establecer procedimientos de depósito, trabajar por la preservación digital de la producción científica e intelectual de la universidad, etc.

En el documento que conmemora el décimo aniversario de la Declaración de Budapest Diez años desde la Budapest Open Access Initiative: hacia lo abierto por defecto $B O A I$, podemos leer:

1. Sobre políticas.

1.1. Cada institución de educación superior debería tener una política que asegure que las versiones revisadas por pares, de todos los futuros artículos científicos de los miembros de la institución, sean depositadas en el repositorio designado por la institución. […]

1.2. Todas las instituciones de educación superior que ofrecen títulos superiores deberían tener una política que asegure que las futuras tesis y disertaciones, una vez aprobados, sean depositados en el repositorio de acceso abierto de la institu ción. $[\cdots]$

1.3. Cada organismo público o privado que financie proyectos de investigación de bería tener una política que asegure que las versiones revisadas por pares de todos los futuros artículos científicos derivados de la investigación financiada sean depo sitadas en un repositorio adecuado y puestos en acceso abierto tan pronto como sea posible."(BOAI, 2013)

En la actualidad existen una serie de portales que recogen las distintas políticas sobre acceso abierto, tanto a nivel nacional (Melibea), como internacional (Roarmap, Sherpa-Juliet).

La encuesta pretendía analizar más detalladamente si las instituciones de REBIUN tienen política de acceso abierto, desde qué fecha, si ésta es de recomendación o mandato y, este punto también es destacado, si existen medios de control de la aplicación de dichas políticas.

Respecto a los resultados de la encuesta, de las 65 instituciones que contestaron, 28 tienen una política de acceso abierto aprobada, 14 están en trámites y 23 instituciones no tienen ninguna política. El órgano que en la mayoría de los casos 
aprueba dichas políticas es el Consejo de Gobierno. Estas políticas pueden ser globales para toda la institución o solo abarcar uno o varios aspectos (tipologías documentales como tesis doctorales o artículos de investigación resultado de ayudas específicas, etc.)

La mayoría de las políticas de acceso abierto se crearon entre 2008 y 2012, siendo este último el año que cuenta con más políticas creadas. Probablemente, la entrada en vigor del Real Decreto 99/2011, de 28 de enero, por el que se regulan las enseñanzas oficiales de doctorado (BOE 10 de febrero de 2011), haya impulsado este aumento.

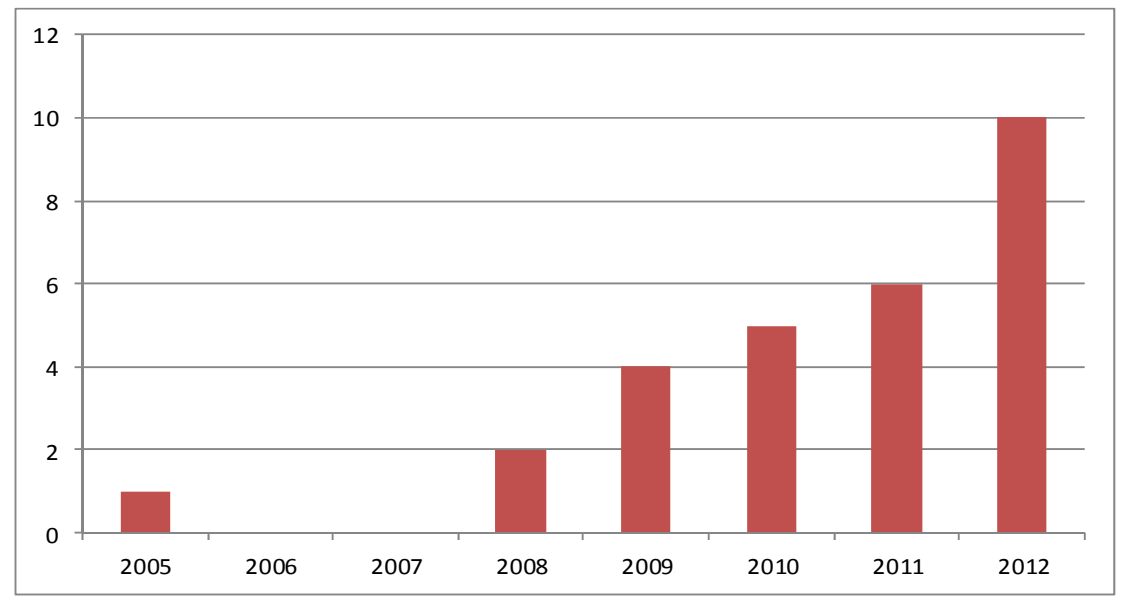

Fig. 9. Año de creación de la política de acceso abierto

Al preguntar por el tipo de política de acceso abierto de la institución, se obtuvieron 41 respuestas (se incluyen las instituciones que ya tienen política y las que están en trámites de aprobación). De ellas 14 son mandato ${ }^{12}, 16$ recomendación $^{13}$ y 11 no lo especifican.

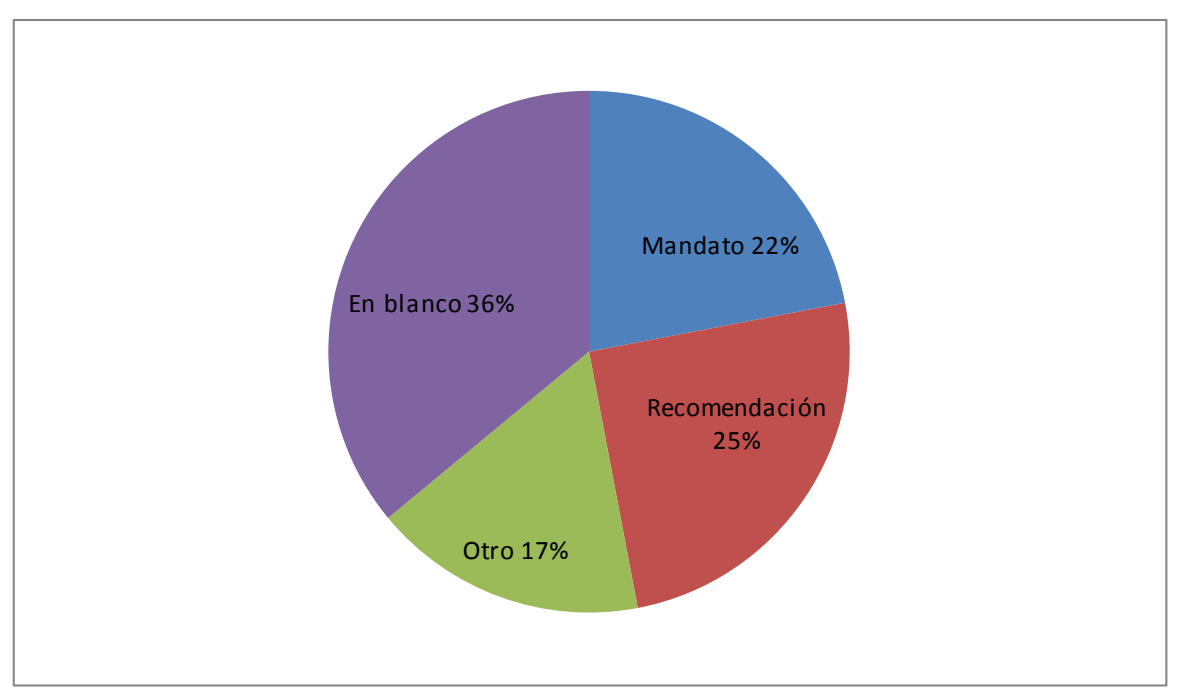

Fig. 10. Tipo de política de acceso abierto 
Aunque en el ámbito internacional se aconsejan los mandatos, en España hay más instituciones con recomendaciones.

Respecto a si las instituciones tienen algún medio de control del cumplimiento de sus políticas de acceso abierto, solo hay 5 respuestas afirmativas.

Podemos mencionar que entre estas 5 respuestas afirmativas, 2 instituciones indican que tienen un medio de control sobre una única tipología documental (tesis doctorales), otra institución tiene un medio de control sobre la producción documental de los grupos de investigación que reciben subvención para la organización de congresos. Las 2 instituciones restantes no especifican los tipos documentales para los que tienen medio de control.

Al preguntar sobre el grado de cumplimiento de dichas políticas, 4 de estas 5 instituciones valoran su grado de cumplimiento con un 5 sobre 5. La institución restante lo valora con un 3 sobre 5 .

\section{Cumplimiento de las políticas nacionales referentes al archivo en repositorios institucionales}

Una cuestión fundamental para que los repositorios institucionales cumplan su objetivo es que sean realmente una imagen de la institución y para ello deben recoger toda o prácticamente toda la documentación que ésta genere, en función de la orientación del repositorio.

En España ya tenemos un marco legal, a nivel nacional, que favorece el depósito de los documentos que reflejen los resultados de la investigación financiada con fondos públicos, la ya mencionada Ley 14/2011 de la Ciencia, la Tecnología y la Innovación y además el Real Decreto 99/2011, de 28 de enero, por el que se regulan las enseñanzas oficiales de doctorado, que en su artículo 14.5, contribuye al depósito en repositorios. A nivel institucional, cada vez son más las universidades españolas que han firmado la Declaración de Berlín y han publicados sus mandatos/recomendaciones a favor del acceso abierto. Pero ¿hasta qué punto se cumple lo recogido en los documentos anteriormente mencionados?

Según los datos recogidos en la encuesta que el Grupo de Trabajo envió a las Universidades que forman parte de REBIUN, exponemos a continuación los principales aspectos relativos al cumplimiento de las políticas nacionales en las universidades españolas. Con respecto a la existencia de medios de control para el cumplimiento del artículo 37 de la Ley 14/2011 por parte de los investigadores de las diferentes instituciones encuestadas, la realidad es evidente: de las 65 instituciones que respondieron sólo 3 tienen algún medio de control, y 15 tienen previsto tenerlo, mientras que 46 expresan claramente carecer de los mismos o desconocerlo. Una de las instituciones no respondió a esta pregunta. 


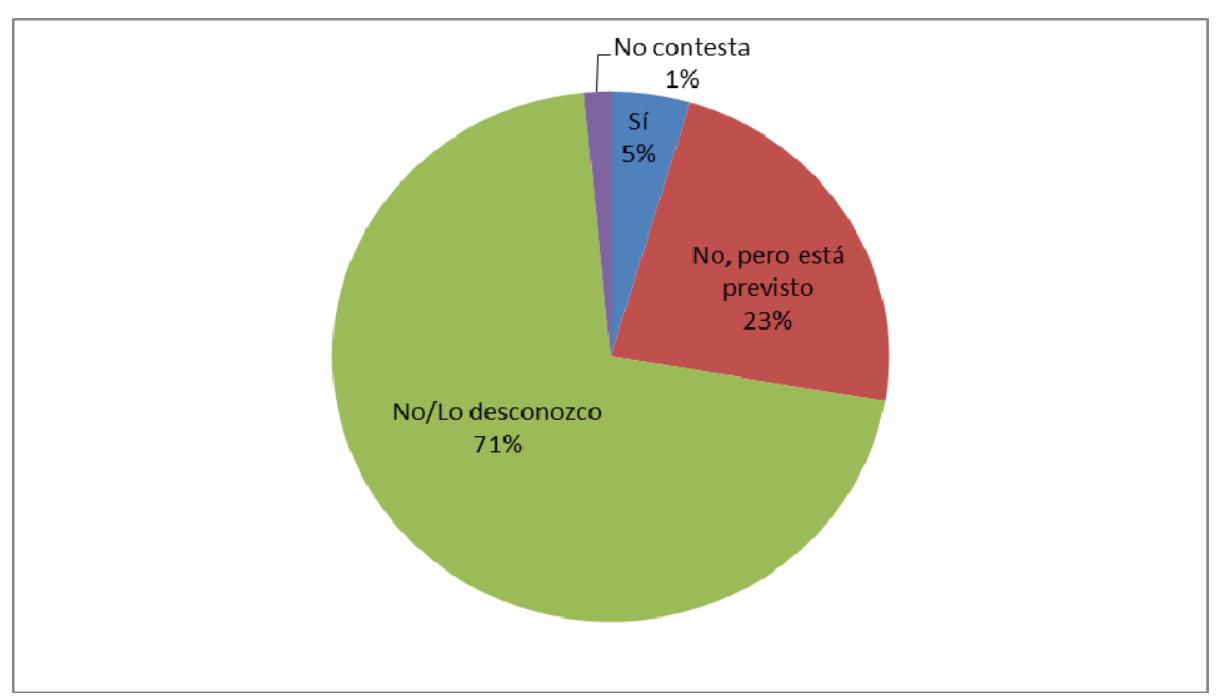

Fig. 11. Control del cumplimiento del art. 37 de la Ley 14/2011

En el caso de aquellas que cuentan ya con dichos mecanismos de control, junto con aquellas otras que tienen previsto tenerlos en un futuro próximo, 9 instituciones especifican el tipo de acciones implementadas o proyectadas. Así, dos universidades afirman realizar un seguimiento por parte del área de Investigación de la Universidad de los proyectos realizados con subvenciones públicas. El resto de las acciones recogidas son únicas para cada una de las instituciones que han respondido a esta pregunta. Así se establece:

- Un análisis por parte de la Biblioteca de los artículos de revista publicados por investigadores de la institución, frente a los depositados en el repositorio.

- El control por parte del área de Postgrado perteneciente al Vicerrectorado de Ordenación Académica y Profesorado y por la OTRI (Oficina de Transferencia de Resultados de Investigación).

- El seguimiento de los proyectos que hayan recibido subvención, aunque no se aclara quién es el responsable de dicho seguimiento.

- La elaboración por parte de la Biblioteca de una base de datos que recoja la producción científica de la Universidad, a partir de los datos contenidos en Scopus, WOK y Dialnet; ésta permitirá conocer la producción científica y contactar con los investigadores para solicitarles el archivo de cada documento.

- Identificar e informar al personal investigador que cuente con financiación de la obligación de publicar la versión final en el repositorio.

- El establecimiento de una normativa propia de la Universidad.

- La memoria de investigación.

En cuanto a la existencia de medios de control para el cumplimiento del artículo 14.5 del Real Decreto 99/2011, algo más de un tercio de las instituciones, en concreto 26 de las 65 que han contestado, tienen algún medio de control; 5 tienen previsto tenerlo; y 33 no lo tienen o lo desconocen. Sólo 1 no contesta a esta cuestión. 


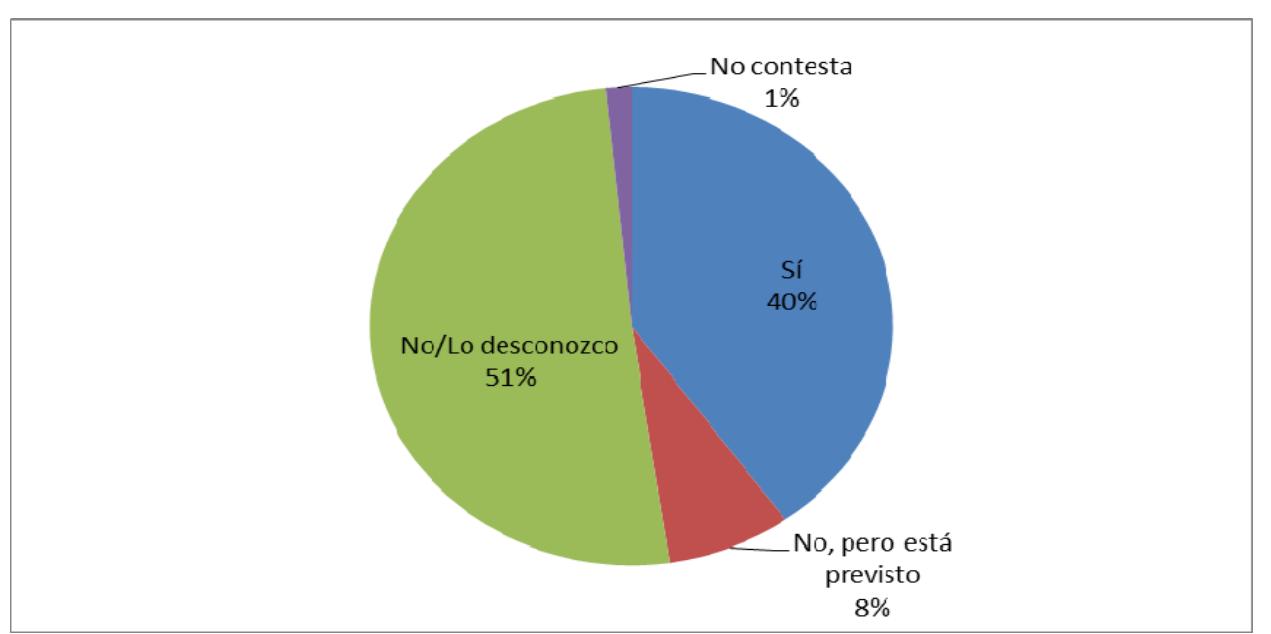

Fig. 12. Control del cumplimiento del art. 14.5 sobre enseñanzas de doctorado

Entre los medios de control ya activos o proyectados destacan los siguientes, por orden de mayor a menor número de implementaciones:

- Control por parte de algún servicio o área de la universidad, fundamentalmente tercer ciclo, área de postgrado o escuela de doctorado. En dos casos este control se realiza en coordinación con la Biblioteca.

- Depósito por defecto incluido en el procedimiento de implementación de las tesis.

- El control se ejerce a través de normativa o reglamento: reglamento de tesis doctorales, normativa de postgrado, normativa de doctorado, reglamento del repositorio.

- Mandato / Depósito obligado.

- Contrato voluntario de depósito.

- Análisis comparativo entre las tesis defendidas en la Universidad y las depositadas en el repositorio.

- El Servicio de Biblioteca realiza un control de todas las tesis depositadas en el repositorio institucional y de todas aquellas cuyos autores han negado el permiso.

- El doctorando debe presentar justificante de haber depositado la tesis para la tramitación del título.

Queda patente que mayoritariamente no existen medios de control para el cumplimiento de las políticas nacionales respecto al archivo en repositorios institucionales. Así, si bien la gran mayoría de las universidades españolas cuentan ya con repositorios, el esfuerzo debe ahora enfocarse hacia la implementación de métodos de control del depósito. 


\section{Otras cuestiones relativas al acceso abierto en las universidades españolas}

\subsection{Uso de los repositorios para procesos de promoción, evaluación, etc.}

Al hilo de las políticas institucionales de acceso abierto y de la necesidad de establecer mecanismos, por parte de la institución, que fomenten el depósito de los resultados de investigación en sus repositorios, nuestra encuesta ha recogido datos sobre el uso que las instituciones dan a sus repositorios, además de los ligados a difusión, visibilidad, organización y preservación de la producción científica.

La cuestión se planteaba de la siguiente manera:

El material depositado en el repositorio es utilizado por la institución para:

-Procesos de promoción

-Evaluación de la actividad científica

- Asignación presupuestaria a los departamentos o grupos de investigación

- Otro

De las 65 instituciones que respondieron a ella, 22 indicaron que utilizan su repositorio para evaluar la producción científica de la institución, 12 para procesos de promoción del personal docente e investigador, 7 como incentivo para asignar presupuestos a los departamentos o grupos de investigación, 2 para gestión de la investigación (Curriculum Vitae Normalizado-CVN; sistemas de gestión de la investigación) y el resto de las instituciones (un 47\%) no tiene en cuenta el repositorio para ninguna de estas acciones.

\subsection{Edición de revistas en acceso abierto}

Ya hemos mencionado anteriormente que dentro del movimiento Open Access la "ruta dorada" se refiere a la publicación en revistas de acceso abierto.

En la encuesta se preguntó si las instituciones editaban revistas en acceso abierto. 48 instituciones (73\%) sí editan este tipo de revistas.

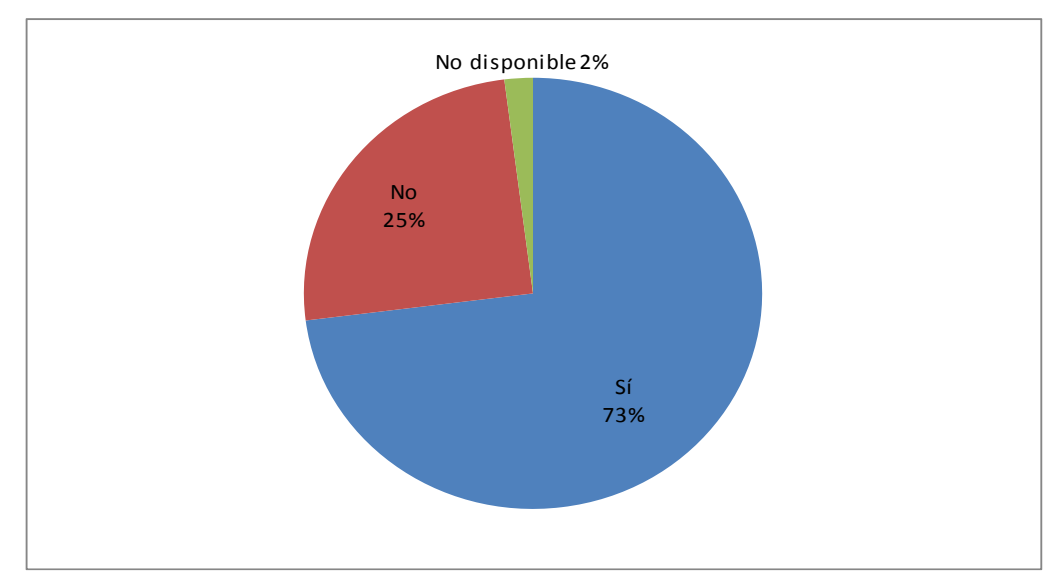

Fig. 13. Edición de revistas en acceso abierto 
No se han planteado más datos respecto a esta cuestión en esta encuesta pero sería interesante un estudio más profundo: número de revistas, número de artículos publicados, temáticas de dichas revistas, qué organismo/servicio se encarga de su edición, fuentes de financiación, si utilizan un software de edición específico, qué licencias de uso utilizan, si contemplan el código de conducta de la OASPA ${ }^{14}$, etc.

\subsection{Servicio de asesoramiento sobre acceso abierto, derechos de autor, licencias, etc.}

Sería muy útil que los investigadores recibiesen asesoramiento sobre cuestiones relacionadas con la edición, y más concretamente con la edición en acceso abierto, que tengan un conocimiento claro de la legislación sobre propiedad intelectual y sean conscientes del valor de los derechos patrimoniales de autor y del uso de las licencias para la publicación, distribución, uso y reutilización de los documentos científicos.

Este asunto se refleja en las Recomendaciones de la European University Association (EUA, 2008) en su punto 4:

“4. Las políticas universitarias deberían incluir el copyright en la gestión de los derechos de propiedad intelectual institucional (DPI). Debería ser responsabilidad de la universidad informar a sus investigadores sobre los DPI y la gestión del copyright para garantizar la más amplia difusión y reutilización de los contenidos digitales de la investigación que han producido. Esto debería incluir una política clara sobre la propiedad y la gestión del copyright de las publicaciones eruditas y de finir procedimientos que aseguren que la institución tiene el derecho de usar el material producido por su personal para futuros propósitos de investigación, educación e instrucción."

Una de las preguntas de la encuesta planteaba si las instituciones tenían establecido un servicio de asesoramiento sobre acceso abierto, derechos de autor, licencias, etc. Se recogieron 33 respuestas afirmativas, 31 negativas y 1 "no disponible”, por tanto la mitad de las instituciones sí disponen de este servicio.

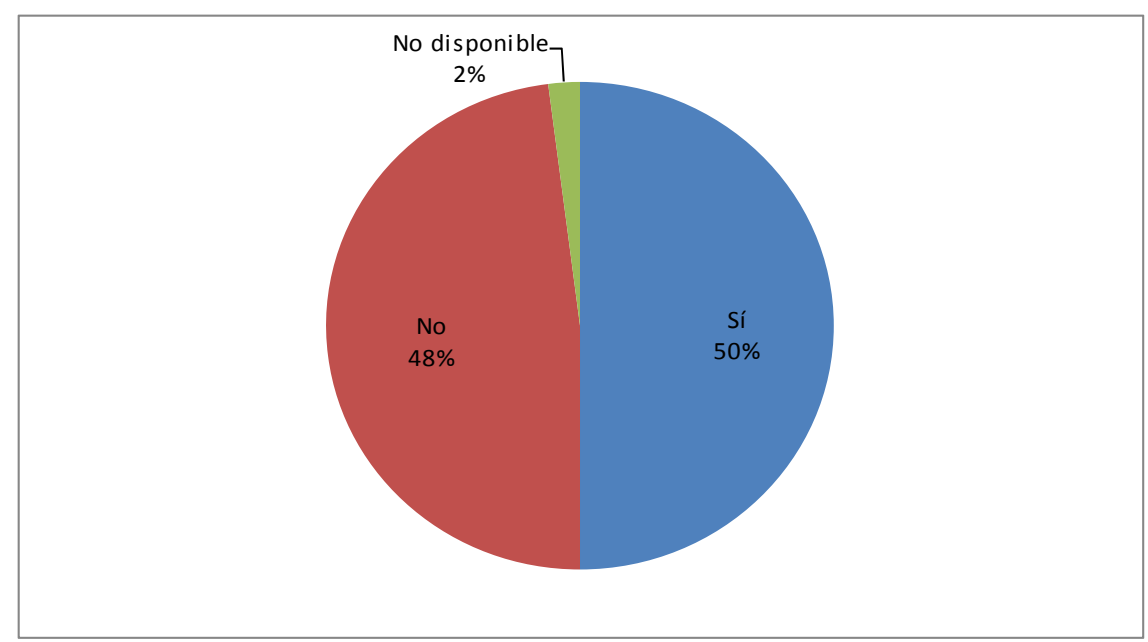

Fig. 14. Servicio de asesoramiento sobre acceso abierto 
El papel de los bibliotecarios en el desempeño de estas tareas es muy importante dentro de las funciones de apoyo a la investigación de las instituciones a las que pertenecen. Los bibliotecarios han de desarrollar nuevos roles y perfiles que se adapten a las nuevas necesidades de nuestras instituciones y que repercutan en el buen desarrollo de las mismas. El asesoramiento en cuestiones relacionadas con el movimiento Open Access, con la creación y mantenimiento de publicaciones de la "ruta dorada”, además de la gestión de los repositorios institucionales, es un gran campo con muchas posibilidades.

\section{Conclusiones y recomendaciones}

\subsection{Conclusiones}

Desde sus inicios hasta la actualidad, el movimiento Open Access en España, y más concretamente su difusión a través de repositorios institucionales en las universidades, ha crecido enormemente ${ }^{15}$. Aun así, sorprende que solo un $47.6 \%$ de las instituciones hayan firmado la Declaración de Berlín hasta la fecha de redacción de este articulo (junio de 2013).

A finales de 2012, 52 universidades españolas afirman contar con repositorio institucional, 8 no tienen repositorio pero tienen prevista su creación y solamente 5 no tienen repositorio y desconocen si se creará en un futuro.

En total se señala la existencia de 482.126 documentos depositados en repositorios españoles hasta la fecha de realización de la encuesta. Tan solo el $27 \%$ de los repositorios tiene más de 10.000 documentos depositados. Así pues, a pesar de contar con un elevado número de repositorios universitarios en España, estos albergan un número de documentos que podemos considerar escaso.

Con respecto a la tipología documental que albergan los repositorios institucionales españoles, se concluye que, aún existiendo gran heterogeneidad, predomina el depósito de artículos de revistas y tesis doctorales.

En la mayor parte de las universidades es el servicio de biblioteca quien se encarga de dotar de contenidos al repositorio, a través del archivo delegado. Algo más de la mitad de los repositorios no cuentan con excepciones para el deposito. Un porcentaje similar establece algún tipo de embargo temporal (fundamentalmente para tesis y artículos).

El uso de licencias está absolutamente generalizado en los repositorios de nuestras instituciones. En cuanto al modelo de licencia utilizado, las licencias Creative Commons son las que se utilizan de forma mayoritaria. El uso de las licencias es de vital importancia, ya que permite a los autores que depositan sus trabajos en los repositorios establecer las condiciones de utilización de los mismos y a los usuarios conocer el uso que pueden hacer de ellos. 
Se constata el todavía escaso número de políticas institucionales de depósito y acceso. Una gran parte de las mismas se crearon entre el 2008 y el 2012, siendo mayoría las instituciones que establecieron sus políticas en 2012 (coincidiendo con la entrada en vigor del Real Decreto 99/2011 que regula las enseñanzas oficiales de Doctorado). Sin embargo, podemos afirmar que mayoritariamente no existen medios de control del cumplimiento del artículo 37 de la Ley 14/2011 de la Ciencia, la Tecnología y la Innovación, ni del artículo 14.5 del R.D. 99/2011, ni de las políticas institucionales. Por tanto es aquí donde hay que realizar un gran esfuerzo de mejora.

Es importante señalar que un elevado porcentaje de instituciones no utiliza el repositorio para otras acciones diferentes de las ligadas a difusión, visibilidad, organización y preservación de la producción científica. Atendiendo a las instituciones que sí utilizan sus repositorios para otros usos, vemos que el empleo del repositorio para la evaluación de la actividad científica es la más extendida, seguida de la utilización para procesos de promoción del personal docente e investigador. Un número muy escaso lo utiliza como incentivo para asignar presupuesto a grupos de investigación o departamentos.

\subsection{Recomendaciones}

El dibujo establecido a través del análisis de la encuesta permite ofrecer una serie de recomendaciones para mejorar el desarrollo e implantación de los repositorios, y en general, del acceso abierto en las universidades españolas, comenzando por el establecimiento de políticas o mandatos de acceso y depósito de documentos en el repositorio institucional, atendiendo, por un lado, a la incorporación del mayor número de documentos posible $\mathrm{y}$, por otro, al respeto a los embargos y otros compromisos editoriales o derechos de terceros.

Para incentivar todos estos puntos se podrían tomar una serie de medidas.

A) Medidas para la creación de políticas de acceso abierto:

1. Dado el bajo porcentaje de instituciones que han apoyado la Declaración de Berlín, podría ser conveniente plantear una firma colectiva de las Universidades apoyada por la CRUE, aprovechando el décimo aniversario de la Declaración.

2. Elaboración de pautas, modelos de procedimientos, para que las universidades que no tengan políticas de acceso abierto dispongan de material que les facilite el camino de la preparación de dichos documentos. 3. También se pueden elaborar modelos para la aplicación más concreta de, por ejemplo, el depósito de tesis doctorales (en aplicación del R.D. 99/2011). 4. Promover el inmediato registro de dichas nuevas políticas en los directorios pertinentes (Melibea, Sherpa-Juliet, etc.)

5. Solicitar a los órganos de gobierno de la universidad que en todas las posibles convocatorias de ayudas para la investigación (a institutos, grupos de investigación, etc.) se incluya el depósito de sus documentos en el repositorio institucional como requisito imprescindible para la concesión, o como mínimo, que puntúe en la baremación de méritos. 
6. Difundir las políticas entre la comunidad universitaria: profesores-investigadores, personal de administración y servicios que apoyan a la investigación, etc.

B) Medidas para cuantificar el grado de cumplimiento de las políticas de depósito y acceso abierto:

El gran problema para los gestores de los repositorios es conocer fidedignamente cuántos documentos han producido los investigadores de su institución y qué documentos son resultado de las investigaciones financiadas por cada uno de los diversos organismos financiadores. Como medidas para subsanar este problema se propone:

1.Es imprescindible la colaboración entre los gestores del repositorio institucional y los responsables de las unidades productoras, sobre todo las vinculadas con la investigación y el doctorado.

2. Recomendar a los investigadores que incluyan siempre la mención de la financiación pública en sus trabajos.

3. Solicitar a los organismos financiadores (Ministerio, FECYT, CCAA, etc.) que proporcionen listados de los artículos afectados de manera que las universidades puedan compararlas con los artículos depositados.

4. Implicar a los vicerrectorados de investigación, a través de los servicios oportunos, en el seguimiento del cumplimiento del depósito de los resultados de investigación en los repositorios institucionales.

5. Otorgar la responsabilidad a una unidad concreta de cada universidad, que se encargue de comprobar y hacer seguimiento de si los trabajos afectados por la normativa se depositan, ofreciendo datos de proyectos aprobados y número de artículos depositados, etc.

6. Implantación de identificadores únicos de autor (ORCID, etc.) para facilitar la labor de relacionar autores y obras evitando la homonimia, etc.

7. Establecimiento de indicadores, cuantificables para verificar el cumplimiento de las políticas:

- Número de tesis leídas en la institución / número de tesis depositadas en el repositorio (aplicación RD. 99/2011);

- Número de documentos referenciados en la memoria de investigación / número documentos depositados en repositorio;

- Número de proyectos 7PM (afectados por cláusula 39) en los que participan investigadores de la institución / número de proyectos con documentos depositados en repositorio; si se quiere ser más preciso: número de publicaciones resultantes de cada proyecto/ número de publicaciones depositadas

- Ídem para proyectos financiados a nivel nacional, autonómico, ayudas de la propia institución, etc. 
C) Medidas para reforzar el papel de los repositorios y del Open Access dentro de la comunidad universitaria:

1. Difusión del repositorio dando a conocer sus beneficios en cuanto a visibilidad, impacto y preservación a nivel de autor y a nivel institucional.

2. Formación para los profesores-investigadores acerca del Open Acces y más concretamente, acerca del repositorio institucional y sus posibilidades para el depósito de documentos: autoarchivo, archivo delegado, etc.

3. Estar al tanto de todas las novedades internacionales en el mundo del Open Access.

4. Implantación, si no lo hubiere, de un servicio de asesoramiento sobre acceso abierto, derechos de autor, licencias, etc. (Ver epígrafe 6.3 del artículo). Formación adecuada para el personal encargado de este servicio.

5. Concienciar a los órganos de gobierno de las instituciones y a las propias agencias de evaluación que deben ser conscientes de la utilidad del repositorio en los procesos de promoción y evaluación de los investigadores, sirviendo de fuente y herramienta para acreditar la producción científica de la institución.

6. Localización, si no lo estuviesen, de series monográficas, revistas de acceso gratuito $^{16}$ online, etc. que se editen en la institución, para mostrarles las ventajas del Acceso Abierto y asesorarles para su conversión en publicaciones de la "ruta dorada".

7. Incentivar la publicación en el repositorio de las publicaciones oficiales de la institución (Boletín Oficial de la Universidad, etc.)

8. Localización de los organizadores de los diversos congresos y otros eventos científicos dentro de la institución, para solicitarles el depósito de las actas en el repositorio institucional.

9. Apoyo al investigador en diversas funciones: elaboración del CVN, preservación digital de su obra, enlaces permanentes (URIs), etc.

10. Unificación de criterios estadísticos entre los diversos repositorios y difusión de dichas estadísticas de visita y descarga.

11. Potenciar el desarrollo de herramientas de vinculación del repositorio con otras aplicaciones institucionales de gestión de la información científica. La integración de los CRIS (Current Research Information System) con los repositorios institucionales es una iniciativa que se está llevando a cabo tanto a nivel europeo como nacional, con la idea de compartir la información de la producción científica de los investigadores, evitando así la duplicidad de trabajos y aunando esfuerzos a la hora de gestionar los datos, para conseguir entre ambos albergar la producción científica completa de la institución con vistas a su evaluación y a su difusión. Los datos se introducen en un único sistema, los servicios de Biblioteca normalizan y validan la descripción bibliográfica de dichos datos, etc. Se potencia la cooperación entre servicios diferentes de la universidad que tienen objetivos comunes: apoyar a los investigadores. En definitiva de lo que se trata es que los repositorios sean una pieza más en la infraestructura institucional integrada de gestión de la información científica y académica. (Martínez, 2011; Rasero, V. y Poveda, A., 2012). 
El futuro, que ya está aquí, se encamina hacia portales que faciliten "el acceso a publicaciones, a información sobre investigadores/grupos/departamento y que den a conocer los proyectos en los que se halla implicada la universidad" (Serrano-Muñoz, 2012). Es decir, que cada vez se proporcionen más valores añadidos, no sólo el texto de los documentos, sino información sobre sus productores, incluir indicadores de WOK, Scopus, Google Citations, mostrar mapas de redes internas y externas de investigadores, publicitar convocatorias de ayudas, etc.

Los repositorios institucionales no solo son importantes como infraestructura tecnológica de soporte al acceso abierto, sino que cumplen o pueden cumplir un papel transcendental en las políticas de visibilidad y promoción de la Universidad. Por ello es fundamental que se potencie su impulso y arroparlo con políticas que permitan no solo su implantación y difusión sino su evaluación y por ende, su mejora constante.

\section{Referencias}

Abadal, E. (2012), Acceso abierto a la ciencia, Universitat Oberta de Catalunya, Barcelona. Disponible en: <http://hdl.handle.net/10760/16863> [Consulta: 20 Junio 2013]

Abadal, E., Anglada, L., Melero, R., Abad, F., Térmens, M. y Rodríguez-Gairín, J.M. (2010), “Open access in Spain”, en: Abadal, E. y Anglada, L. (Eds.), Open access in Southern European countries, FECYT, Madrid, pp. 101-115. Disponible en:

$<$ www.accesoabierto.net/sites/accesoabierto.net/files/OASouthEurope_07_Spain.pdf> [Consulta: 20 Junio 2013].

Abadal, E.; Ollé Castellà, C.; Abad-García, F.; Melero, R. (2013), "Políticas de acceso abierto a la ciencia en las universidades españolas”, Revista Española de Documentación Científica, Vol. 36, No. 2, eoo7. Disponible en:

<http://dx.doi.org/10.3989/redc.2013.2.933> [Consulta: 25 Junio 2013]

Barrueco, J.M., García-Testal, C. (2009). "Repositorios institucionales universitarios: evolución y perspectivas”, ponencia presentada en Fesabid, XI Jor-na-das Españolas de Documentación. 20-22 Mayo, Zaragoza. Disponible en:

<www.fesabid.org/zaragoza2009/actas-fesabid-2009/99-107.pdf> [Consulta: 20 Junio 2013].

Berlin Declaration on Open Access to Knowledge in the Sciences and Humanities (2003). Disponible en: $<$ www.zim.mpg.de/openaccess-berlin/berlin_declaration.pdf > [Consulta: 20 Junio 2013].

Bethesda Statement on Open Access Publishing (2003). Disponible en:

$<$ www.earlham.edu/ peters/fos/bethesda.htm > [Consulta: 20 Junio 2013].

BOAI. Budapest Open Access Initiative (2002). Disponible en: $<$ www.soros.org/openaccess $>$ [Consulta: 20 Junio 2013].

BOAI. Budapest Open Access Initiative (2013). Diez años desde la Budapest Open Access Initiative: hacia lo abierto por defecto. Disponible en:

$<$ www.budapestopenaccessinitiative.org/boai-10-translations/spanish $>$ [Consulta: 17 junio 2013]

BuscaRepositorios. Disponible en:

$<$ www.accesoabierto.net/repositorios/ $>$ [Consulta: 20 Junio 2013]. 
MEI, II, Vol. 4, n $^{\circ}$, pág. 78

Comisión Europea (2012), Información científica: el acceso libre o abierto a los resultados de la investigación impulsará la capacidad de innovación europea. Disponible en:

<http://europa.eu/rapid/press-release_IP-12-790_es.htm> [Consulta: 20 Junio 2013].

Creative Commons España. Licencias. Disponible en:

$<$ http://es.creativecommons.org/licencia/> [Consulta: 20 Junio 2013].

España. Ley 14/2011, de 1 de junio, de la Ciencia, la Tecnología y la Innovación, Boletín Oficial del Estado, 2 de Junio 2011, No. 131, pp. 54387-54455. Disponible en:

$<$ www.boe.es/boe/dias/2011/06/o2/pdfs/BOE-A-2011-9617.pdf> [Consulta: 20 Junio 2013].

España. Real Decreto 99/2011, de 28 de enero, por el que se regulan las enseñanzas oficiales de doctorado, Boletín Oficial del Estado, 10 Febrero 2011, No. 35, pp. 13909-13926. Disponible en:

$<$ www.boe.es/boe/dias/2011/02/10/pdfs/BOE-A-2011-2541.pdf> [Consulta: 20 Junio 2013].

EUA: European University Association (2008), Recommendations from the EUA Working Group on Open Access. Disponible en:

$<$ www.eua.be/typo3conf/ext/bzb_securelink/pushFile.php?cuid=2122\&file=fileadmin/user_upload/ files/Policy_Positions/

Recommenda-

tions_Open_Access_adopted_by_the_EUA_Council_on_26th_of_March_2008_final.pdf> [Consulta: 20 Junio 2013]. Versión en castellano: "Recomendaciones del Working Group on Open Access del EUA aprobadas por el EUA Council el 26 de marzo de 2008 (Universidad de Barcelona, España), traducción castellana realizada por Noelia Martínez a partir de la traducción en catalán de Núria Comellas. Disponible en:

<http://hdl.handle.net/2072/5386> [Consulta: 25 Junio 2013]

European Commission (2006), European Research Advisory Board. Final Report. EURAB 06.049 Scientific publication: policy on open access. Disponible en:

<http://ec.europa.eu/research/eurab/pdf/eurab_scipub_report_recomm_dec06_en.pdf> [Consulta: 20 Junio 2013].

European Commission (2008), European Research Area. Open Access Pilot in FP7. Disponible en: <http://ec.europa.eu/research/science-society/document_library/pdf_06/open-access-pilot_en.pdf> [Consulta: 20 Junio 2013].

European Research Council (2007), ERC Scientific Council Guidelines for Open Access. Disponible en: $<$ http://erc.europa.eu/sites/default/files/document/file/erc_scc_guidelines_open_access.pdf> [Consulta: 20 Junio 2013].

Frías, J.A. (2006), “Las universidades españolas y la iniciativa OAI”. En: Jornadas OS-Repositorios, Zaragoza.

Martínez, Didac. (2011), "El siguiente paso en el desarrollo de los repositorios: integración con la infraestructura institucional de gestión de la información científica", ponencia presentada en la Jornada técnica sobre CRIS y repositorios. UOC2011. Disponible en:

<http://hdl.handle.net/10609/10621> [Consulta: 26 Junio 2013].

Melero, R. (2008a), "El paisaje de los repositorios institucionales open access en España”, BiD: textos universitaris de biblioteconomia i documentació, No. 20. Disponible en:

$<$ www.ub.edu/bid/20meler4.htm> [Consulta: 20 Junio 2013].

Melero, R. (2008b), "La proyección de los repositorios institucionales”, ponencia presentada en 3as Jornadas OS-Repositorios. 10-12 diciembre, Madrid. Disponible en:

<http://eprints.ucm.es/8480/2/rememelero.pdf> [Consulta: 20 Junio 2013]. 
Melero, R., Abadal, E., Abad-García, F. y Rodríguez-Gairín, J.M. (2009), Situación de los repositorios institucionales en España: informe 2009. Disponible en:

$<$ www.accesoabierto.net/sites/accesoabierto.net/files/Informe2009-Repositorios_o.pdf> [Consulta: 20 Junio 2013].

Melibea. Disponible en:

$<$ www.accesoabierto.net/politicas/> [Consulta: 20 Junio 2013].

OASPA. Open Access Scholarly Publishers Association. Code of conduct. Disponible en:

<http://oaspa.org/membership/code-of-conduct/> [Consulta: 20 Junio 2013]

OpenAIRE. Open Access infrastructure for Research in Europe (2009). Disponible en: $<$ www.openaire.eu/index.php?lang=en-GB $>$ [Consulta: 20 Junio 2013].

OpenDOAR. Disponible en:

$<$ www.opendoar.org/> [Consulta: 20 Junio 2013].

Plos One. Disponible en:

$<$ www.plosone.org/> [Consulta: 20 Junio 2013].

Rasero, V. y Poveda, A. (2012), "Integración del sistema de gestión de la investigación y el repositorio institucional”, ponencia presentada en IV Jornada de buenas prácticas: Servicios de apoyo a la investigación en las bibliotecas universitarias. 30 Octubre, Madrid. Disponible en:

<http://www.consorciomadrono.es/noticias_eventos/2012/buenasPracticas/

integracion_uc3m_jornadas_madrono_oct_2012.pdf > [Consulta: 27 Junio 2013].

REBIUN (2004), Declaración de REBIUN en apoyo del modelo de acceso abierto. Disponible en: $<$ http://oaulpgc.wordpress.com/2009/06/22/declaracion-de-rebiun-en-apoyo-del-modelo-de-accesoabierto/> [Consulta: 20 Junio 2013].

REBIUN (2011), III Plan estratégico 2020: Construyendo juntos el futuro de las bibliotecas, de la información y de la ciencia en un mundo global. Disponible en:

<http://www.mcu.es/bibliotecas/docs/MC/ConsejoCb/CTC/Bib_Univ/Planestrategico2020.pdf> [Consulta: 20 Junio 2013].

ROAR. Registry of Open Access Repositories. Disponible en: $<$ http://roar.eprints.org/> [Consulta: 20 Junio 2013].

ROARMAP. Disponible en:

<http://roarmap.eprints.org/> [Consulta: 20 Junio 2013]

Serrano-Muñoz, Jordi (2012), "FUTUR: El portal de la producción científica”, ponencia presentada en IV Jornada de buenas prácticas: Servicios de apoyo a la investigación en las bibliotecas universitarias. 30 Octubre, Madrid. Disponible en:

<http://www.consorciomadrono.es/noticias_eventos/2012/buenasPracticas/Futur_UPC.pdf> [Consulta: 27 Junio 2013].

SHERPA-JULIET. Disponible en:

$<$ www.sherpa.ac.uk/juliet/> [Consulta: 20 Junio 2013]

Unión Europea (2007), Séptimo Programa Marco (2007-2013). Disponible en:

<http://europa.eu/legislation_summaries/energy/european_energy_policy/i23022_es.htm>

[Consulta: 20 Junio 2013]. 


\section{Anexo 1. Encuesta}

1. Universidad

2. Indique el enlace web de la Institución a la que pertenece

3. ¿Tiene Repositorio Institucional (RI)?

4. Indique el nombre del RI

5. Indique el enlace web del RI

6. ¿Cuál es el año de creación del RI?

7. Tipo de documentos que alberga el Repositorio

Artículos de revistas

Audiovisuales

Capítulos de libros

Comunicaciones a congresos, posters, etc.

Datasets

Documentación institucional

Fondo antiguo

Libros

Objetos de aprendizaje

Patentes

Pre-prints

Referencias bibliográficas

Revistas editadas por la institución

Tesis doctorales

Trabajos Fin de Grado

Trabajos Fin de Máster

Working papers

Otro

8. ¿Se utiliza algún modelo de licencia que permita el uso libre de los contenidos en el repositorio? Sí/no

8.1. Si la repuesta anterior fue sí. Especifique cuales

9. ¿Tiene prevista su Universidad acciones o planes de marketing y divulgación del Repositorio?

10. Indique el número de documentos depositados en el Repositorio

11. Deposita su Universidad documentación en otros repositorios

12. ¿Ha firmado su institución la Declaración de Berlín?

13. ¿Quién ha firmado la Declaración?

14. Indique el año en el que se firmó la Declaración

15. ¿Tiene definida una/varias política/s Open Access?

16. Indique los enlaces Web dónde se publican la/s política/s de Open Access (reglamentos, normativas, etc.)

17. ¿Quién ha decidido la adopción de políticas de acceso abierto?

18. ¿Tiene su institución algún medio de control del cumplimiento de sus políticas de acceso abierto?

19. Especifique el medio de control que posee su institución, respecto al cumplimiento de sus políticas de acceso abierto

20. ¿Cuál es el grado de cumplimiento de las políticas de su institución?, donde 5 es el grado máximo de cumplimiento y 1 el grado mínimo. 
21. Indique el año de creación de la/s política/s de acceso abierto

22. Indique el tipo de política/s de acceso abierto de su institución

23. ¿Cómo se articula el depósito en su institución?

24. ¿Existen excepciones para el depósito?

25. Especifique cuáles son las excepciones para el depósito

26. ¿Tiene su institución establecidos embargos temporales hasta el acceso abierto a los documentos?

26.1. Indique el periodo

26.2 Indique el tipo de material

27. ¿Qué política de depósito y acceso de los materiales tiene establecida su institución? Si depende del tipo de materiales, especifique cuales.

Depósito y acceso inmediato

Depósito después de un embargo

Depósito inmediato y acceso después de un embargo

Otro

28. En caso de tener una política referente a artículos de investigación ¿Cuándo deben depositarse para ser publicados?

En el momento de ser aceptados para publicar

Cuando el artículo es publicado

Transcurrido un período de embargo de 6 meses

Transcurrido un período de embargo de 1 año

Depende de la política de la editorial

Otro

Sin respuesta

29. ¿Tiene su institución algún medio de control del cumplimiento del artículo 37 de

la Ley 14/2011 de la Ciencia, la Tecnología y la Innovación por parte de sus investigadores?

$\mathrm{Si}$

No, pero está previsto

No/Lo desconozco

Sin respuesta

30. Especifique el medio de control que tiene su institución para el cumplimiento del art. 37 de la ley $14 / 2011$

31. ¿Tiene su institución algún medio de control del cumplimiento del artículo 14.5

del Real Decreto 99/2011 que regula las enseñanzas de doctorado?

$\mathrm{Si}$

No, pero está previsto

No/Lo desconozco

Sin respuesta

32. Especifique el medio de control que posee su institución para el cumplimiento del artículo 14.5 del Real Decreto 99/201

33. ¿Edita su institución revistas en acceso abierto?

$\mathrm{Si}$

No

Sin respuesta

34. ¿Tiene establecido su institución un servicio de asesoramiento sobre acceso abierto, derechos de autor, licencias, etc.? 
MEI, II, Vol. 4, nº 6, pág. 82

$\mathrm{Si}$

No

Sin respuesta

35. El material depositado en el repositorio es utilizado por la institución para

Procesos de promoción

Evaluación de la actividad científica

Asignación presupuestaria a los departamentos o grupos de investigación

Otro

\section{9.-Notas}

1. Fundación creada en 1993 por George Soros que instó a promover sociedades que, amparadas por políticas gubernamentales, permitieran dar soporte a proyectos relacionados con temas sociales de interés.

2. PLOS. Disponible en: <www.plos.org/about/what-is-plos/early-history/> [Consulta: 20 junio 2013]

3. Otras declaraciones relevantes de apoyo al acceso abierto son:

-European Cultural Heritage Online (ECHO), (Agosto 2003). Statement of Purpose. Disponible en:

<http://echo.mpiwg-berlin.mpg.de/policy/oa_basics/statement> [Consulta: 20 Junio 2013] -Association of College \& Research Libraries (ACRL), (Agosto 2003) Principles and Strategies for the Reform of Scholarly Communication. Disponible en: <http:// w w w . a l a . o r g / a c r 1 / publications/whitepapers/principlesstrategies $>$ [Consulta: 20 Junio 2013]

-UN. World Summit on the Information Society, (Diciembre 2003) Declaración de P r in c i p i o s . Construir la sociedad de la información: un desafío global para el nuevo milenio. Disponible en: http://www.itu.int/wsis/docs/geneva/official/dop-es.html y Plan de acción. Disponible en: http://www.itu.int/wsis/docs/geneva/official/poa-es.html [Consulta: 26 Junio 2013]

-Organisation for Economic Co-operation and Development (OECD) (Enero 2004) Declaration on Access to Research Data From Public Funding. Disponible en:

$<$ http://www.oecd.org/sti/sci-tech/38500813.pdf> [Consulta: 20 Junio 2013]

-The International Federation of Library Associations and Institutions (IFLA) (Febrero 2004) released the IFLA Statement on Open Access to Scholarly Literature and Research Documenta tion. Disponible en: <http://www.ifla.org/publications/ifla-statement-on-open-access-to-scholarly -literature-and-research-documentation> [Consulta: 20 Junio 2013]

-UK. House of Commons, (Julio 2004) Scientific publications: Free for all?. Disponible en: <www.publications.parliament.uk/pa/cm200304/cmselect/cmsctech/399/399.pdf> [Consulta: 20 Junio 2013]

-UK. House of Commons, (Julio 2004) Peer review in scientific publications. Disp o n i b l e e n : <www.publications.parliament.uk/pa/cm201012/cmselect/cmsctech/856/856.pdf> [Consulta: 20 Junio 2013]

-UNESCO, (Julio 2012) Declaración de Paris sobre los recursos educativos abiertos. Disponible en: <www.unesco.org/new/fileadmin/MULTIMEDIA/HQ/CI/CI/pdf/Events/Paris\%20OER\% 20Declaration_01.pdf> [Consulta: 20 Junio 2013]

4. Existe igualmente la "Ruta dorada" o publicación en revistas de acceso abierto y r e c i e n t e mente se habla de una nueva ruta, la "Ruta platino" que defiende que todas las publicaciones deberían ser de acceso abierto y que se pague por determinados servicios de valor añadido.

5. "La Comisión: 
-definirá el acceso abierto a las publicaciones revisadas por pares como principio general de la iniciativa Horizonte 2020, bien mediante el acceso abierto a la publicación (acceso abierto por la vía dorada), bien mediante el autoarchivo (acceso abierto por la vía verde);

-fomentará el acceso libre a los datos de la investigación (resultados experimentales, observaciones e información generada por ordenador, etc.) y establecerá un marco piloto en Horizonte 2 o 20 , teniendo en cuenta la existencia de preocupaciones legítimas en relación con la intimidad, los intereses comerciales y las cuestiones ligadas a grandes volúmenes de datos;

-creará y apoyará infraestructuras electrónicas para acoger y compartir la información científica (publicaciones y datos) que sean interoperables a escala europea y mundial;

-ayudará a los investigadores a cumplir sus obligaciones de acceso abierto y fomentará una cultura de puesta en común.” (Comisión Europea, 2012)

6. 14.5. Una vez aprobada la tesis doctoral, la universidad se ocupará de su archivo en f o $\mathrm{r}$ m a t o electrónico abierto en un repositorio institucional y remitirá, en formato electrónico, un ejemplar de la misma así como toda la información complementaria que fuera necesaria al Ministerio de Educación a los efectos oportunos.

14.6. En circunstancias excepcionales determinadas por la comisión académica del p r o g r a m a , como pueden ser, entre otras, la participación de empresas en el programa o Escuela, la existencia de convenios de confidencialidad con empresas o la posibilidad de generación de patentes que recaigan sobre el contenido de la tesis, las universidades habilitarán procedimientos para desarrollar los apartados 4 y 5 anteriores que aseguren la no publicidad de estos aspectos.

Disposición transitoria primera. Doctorandos conforme a anteriores ordenaciones.

A los doctorandos que en la fecha de entrada en vigor de este real decreto hubiesen iniciado estudios de doctorado conforme a anteriores ordenaciones, les será de aplicación las disposiciones reguladoras del doctorado y de la expedición del título de Doctor por las que hubieren iniciado dichos estudios. En todo caso, el régimen relativo a tribunal, defensa y evaluación de la tesis doctoral previsto por el presente real decreto será aplicable a dichos estudiantes a partir de un año de su entrada en vigor.

7. Preámbulo I. La presente ley incorpora un conjunto de medidas de carácter novedoso que persiguen situar a la legislación española en materia de ciencia y tecnología e innovación en la vanguardia internacional. Entre estas medidas para una «Ciencia del siglo XXI» destacan la incorporación del enfoque de género con carácter transversal; el establecimiento de derechos y deberes del personal investigador y técnico; el compromiso con la difusión universal del conocimiento, median te el posicionamiento a favor de las políticas de acceso abierto a la información científica [...]

Preámbulo VI. Una de las novedades de la ley es la previsión que establece sobre publicación en acceso abierto, que dispone que todos los investigadores cuya actividad haya sido finan ciada mayoritariamente con los Presupuestos Generales del Estado están obligados a publicar en acceso abierto una versión electrónica de los contenidos acepta dos para publicación en publicaciones de investigación. Para su desarrollo, se encomienda a los agentes del Sistema el establecimiento de repositorios institucionales de acceso abierto.

Artículo 37. Difusión en acceso abierto.

1. Los agentes públicos del Sistema Español de Ciencia, Tecnología e Innovación impulsarán el desarrollo de repositorios, propios o compartidos, de acceso abierto a las publicaciones de su personal de investigación, y establecerán sistemas que permitan conectarlos con iniciativas similares de ámbito nacional e internacional.

2. El personal de investigación cuya actividad investigadora esté financiada mayoritariamente c o $\mathrm{n}$ fondos de los Presupuestos Generales del Estado hará pública una versión digital de la versión final de los contenidos que le hayan sido aceptados para publicación en publicaciones de investigación seriadas o periódicas, tan pronto como resulte posible, pero no más tarde de doce meses después de la fecha oficial de publicación. 
MEI, II, Vol. 4, nº 6, pág. 84

3. La versión electrónica se hará pública en repositorios de acceso abierto reconocidos en el campo de conocimiento en el que se ha desarrollado la investigación, o en repositorios institucionales de acceso abierto.

4. La versión electrónica pública podrá ser empleada por las Administraciones Públicas en sus p r ocesos de evaluación.

5. El Ministerio de Ciencia e Innovación facilitará el acceso centralizado a los repositorios, y su conexión con iniciativas similares nacionales e internacionales.

6. Lo anterior se entiende sin perjuicio de los acuerdos en virtud de los cuales se hayan podido atribuir o transferir a terceros los derechos sobre las publicaciones, y no será de aplicación cuando los derechos sobre los resultados de la actividad de investigación, desarrollo e innovación sean susceptibles de protección.

8. BuscaRepositorios. Disponible en: <www.accesoabierto.net/repositorios $>$ [Consulta: $20 \mathrm{Ju}-$ nio 2013].

9. OpenDOAR. Disponible en: <www.opendoar.org > [Consulta: 20 Junio 2013].

10.Roar: Registry of Open Access Repositories. Disponible en: <http://roar.eprints.org> [Consulta: 20 Junio 2013].

11.A finales de 2012 firmaron la Universidad de Valladolid y la Universidad Autónoma de Barcelona. En lo que llevamos de 2013 se han adherido la Universidad de Jaén, la Universidad de Málaga, la Universidad CEU Cardenal Herrera y la Universidad de Zaragoza. Open Access at the Max Planck Society. Signatories. Disponible en:

<http://oa.mpg.de/lang/en-uk/berlin-prozess/signatoren> [Consulta: 25 Junio 2013]

12.Mandato: Obligatoriedad impuesta por una institución de depositar en su repositorio el resultado de su actividad académica e investigadora. Las políticas de mandato reflejan el compromiso de la institución a favor de la difusión de la investigación en acceso abierto.

13.Recomendación: Política institucional a favor del acceso abierto mediante la cual se aconseja e insta, pero no se obliga, a los autores a depositar el resultado de su producción académica y científica en el repositorio de la institución.

14.OASPA. Open Access Scholarly Publishers Association. Code of conduct. Disponible en: <http://oaspa.org/membership/code-of-conduct/> [Consulta: 20 Junio 2013]

15.Pueden consultarse los trabajos de Melero (2008), Frías (2006), Barrueco y García-Testal (2009) y Abadal, et al (2013) para comprobar los avances. Especialmente los dos últimos artículos citados resultan reveladores, al centrarse, como en este trabajo, solo en el ámbito de los repositorios universitarios.

16.Hay que diferenciar entre acceso libre o gratuito en Internet y acceso abierto. 


\begin{tabular}{|c|c|c|c|c|c|c|c|c|}
\hline 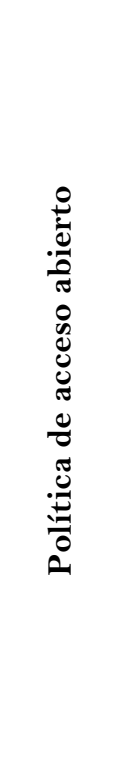 & 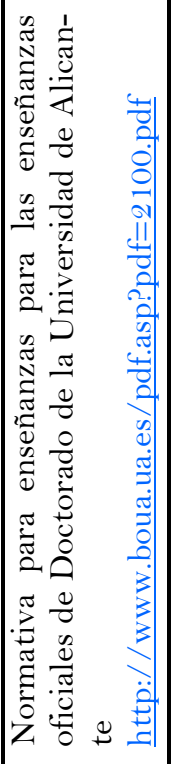 & 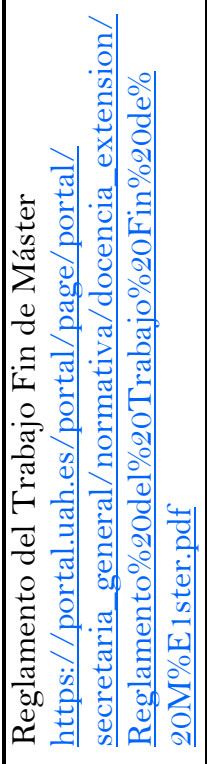 & & 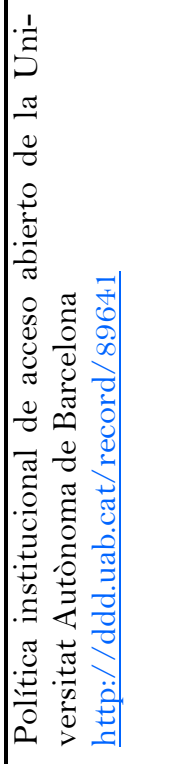 & & 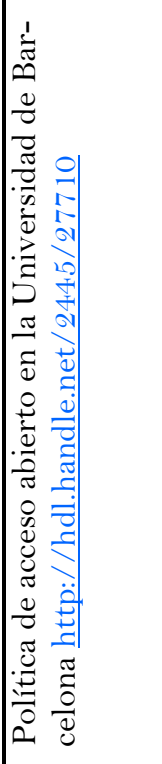 & & \\
\hline 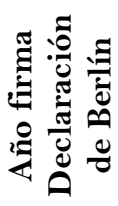 & $\mid \begin{array}{l}0 \\
\& \\
0\end{array}$ & $\mid \begin{array}{l}0 \\
\& \\
0\end{array}$ & O & 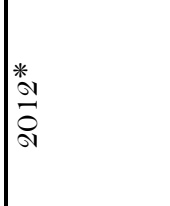 & $\begin{array}{l}0 \\
\& \\
o\end{array}$ & 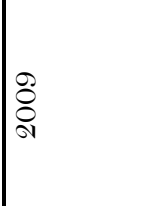 & $\stackrel{o}{z}$ & $\begin{array}{l}0 \\
z\end{array}$ \\
\hline 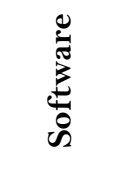 & 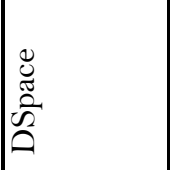 & 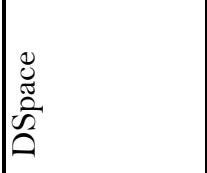 & 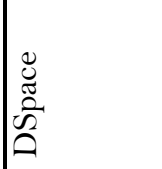 & 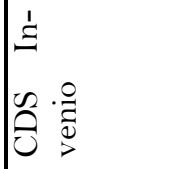 & 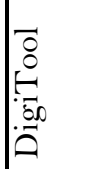 & 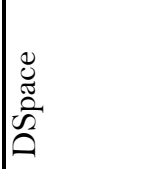 & 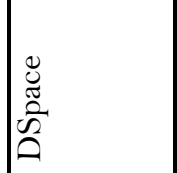 & 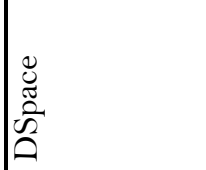 \\
\hline 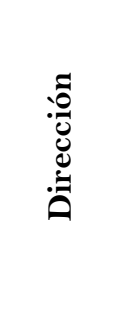 & $\mid$ & 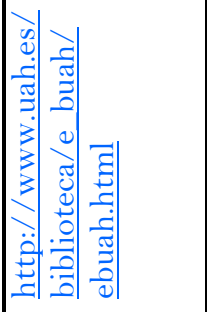 & 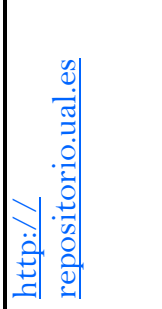 & 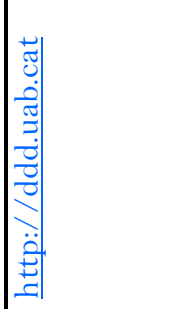 & 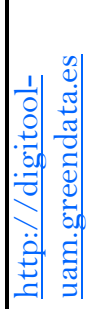 & 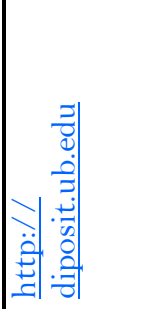 & $\mid$\begin{tabular}{l|}
$\mid$ \\
0 \\
0 \\
0 \\
0 \\
0 \\
0 \\
0 \\
0 \\
0 \\
0 \\
0 \\
0 \\
0
\end{tabular} & 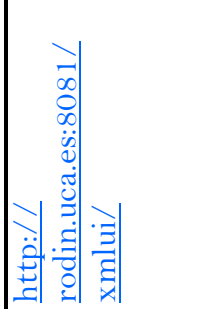 \\
\hline 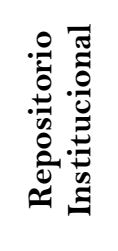 & 忿 & 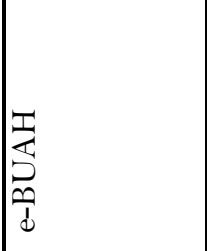 & 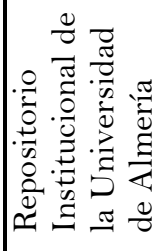 & 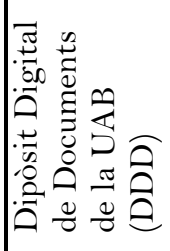 & 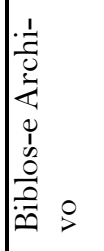 & 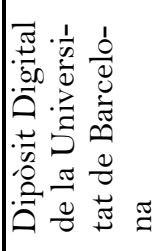 & 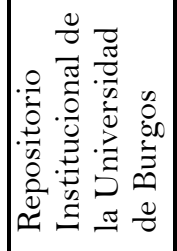 & 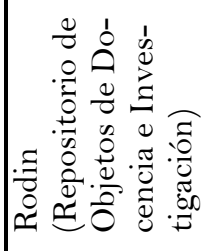 \\
\hline 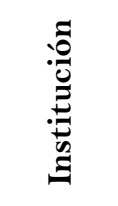 & 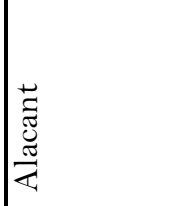 & $\frac{\frac{\pi}{\pi}}{\frac{\pi}{\pi}}$ & 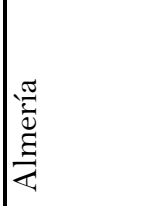 & 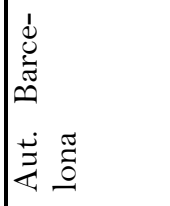 & 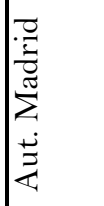 & 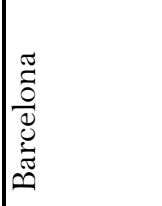 & \begin{tabular}{|l}
0 \\
0 \\
0 \\
$\vdots$ \\
$\vdots$ \\
0
\end{tabular} & 谞 \\
\hline
\end{tabular}




\begin{tabular}{|c|c|c|c|c|c|}
\hline 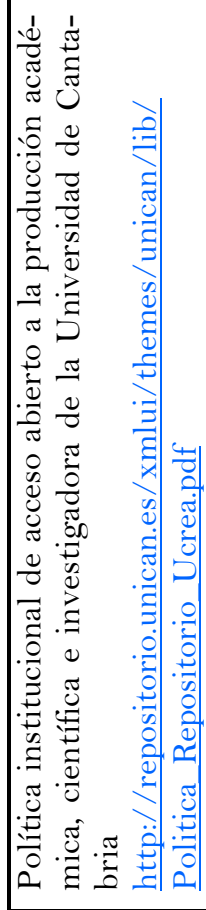 & & 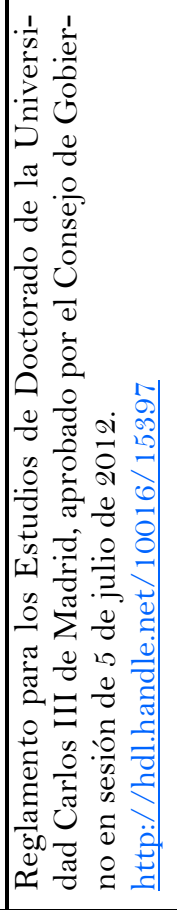 & 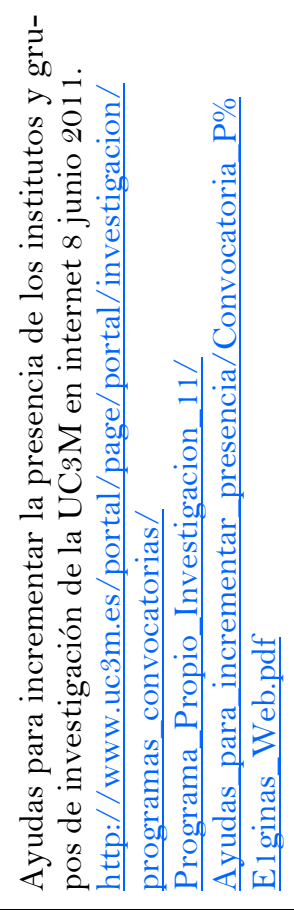 & 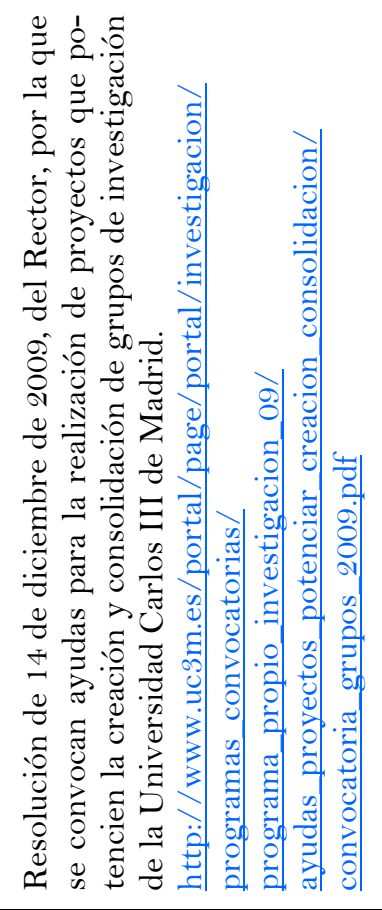 & 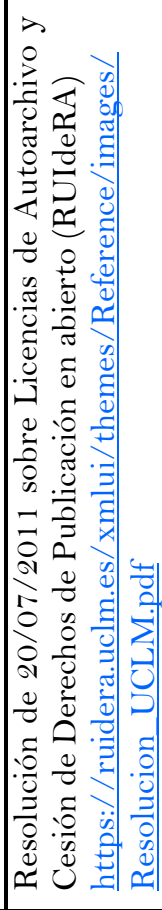 \\
\hline $\begin{array}{l}0 \\
Z\end{array}$ & 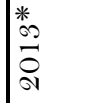 & $\begin{array}{l}0 \\
\& \\
8\end{array}$ & & & $\begin{array}{l}0 \\
z\end{array}$ \\
\hline 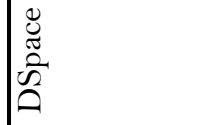 & 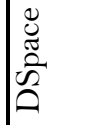 & 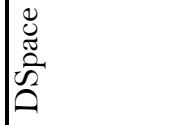 & & & 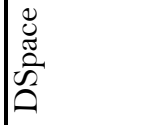 \\
\hline 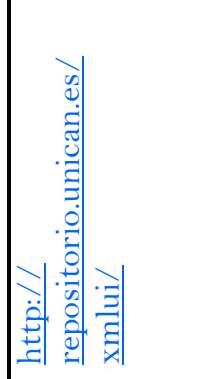 & 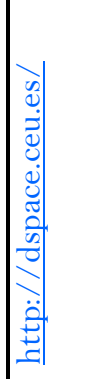 & 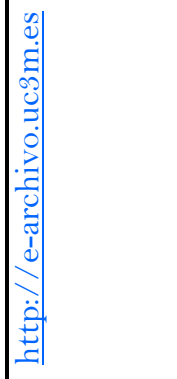 & & & 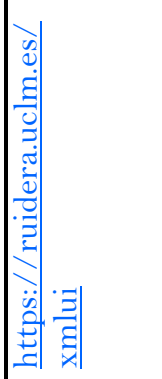 \\
\hline صَّ & 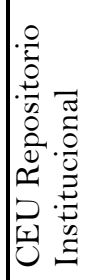 & 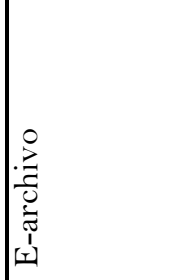 & & & 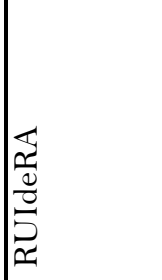 \\
\hline 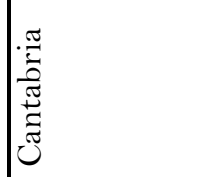 & 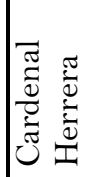 & 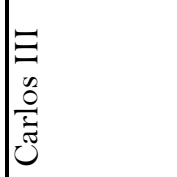 & & & 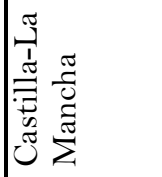 \\
\hline
\end{tabular}




\begin{tabular}{|c|c|c|c|c|c|c|c|c|c|c|}
\hline & & \begin{tabular}{|l} 
\\
\\
\\
\\
\end{tabular} & & & 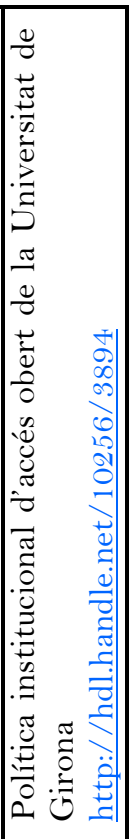 & 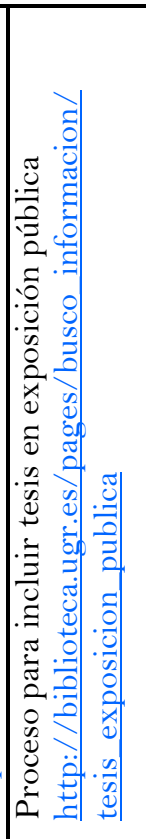 & & & & \\
\hline \& & $\mid$\begin{tabular}{l}
0 \\
\multirow{o}{*}{} \\
\end{tabular} & 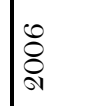 & $\AA$ & Z & 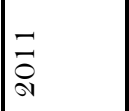 & 号 & | & Zे & z & 多 \\
\hline 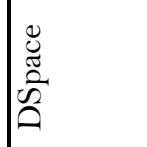 & 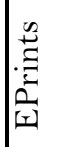 & 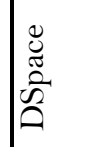 & 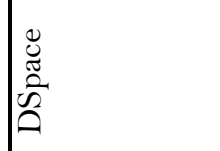 & 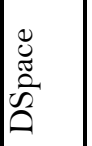 & 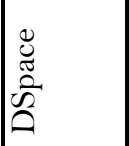 & 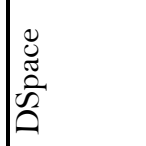 & $\mid \begin{array}{l}\mathscr{\mathscr { U }} \\
\tilde{\widetilde{n}} \\
\widetilde{\Omega}\end{array}$ & 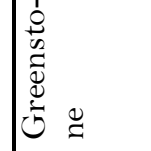 & 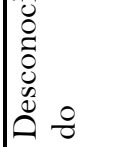 & $\mid \begin{array}{l}\tilde{\mathscr{U}} \\
\tilde{\tilde{n}} \\
\tilde{\Omega}\end{array}$ \\
\hline 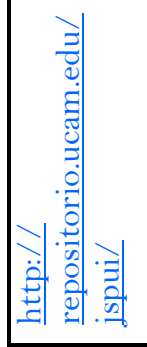 & 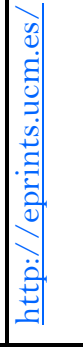 & 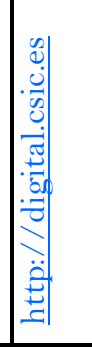 & $\mid \begin{array}{c}0 \\
0 \\
0 \\
0\end{array}$ & 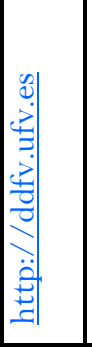 & 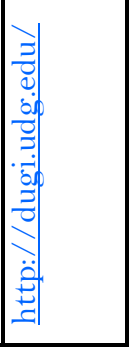 & 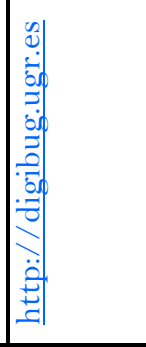 & $\begin{array}{ll}0 \\
0 \\
0\end{array}$ & 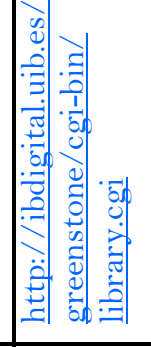 & 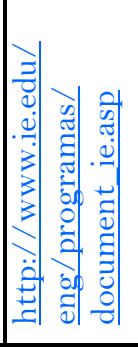 & $\begin{array}{ll}0 \\
0 \\
0 \\
0\end{array}$ \\
\hline 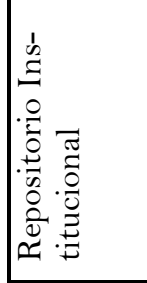 & 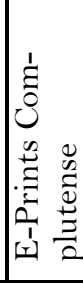 & 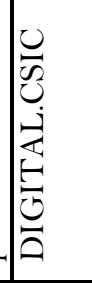 & 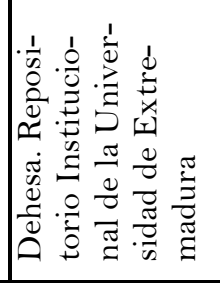 & 窟 & $\begin{array}{l}\overrightarrow{6} \\
\overrightarrow{0}\end{array}$ & 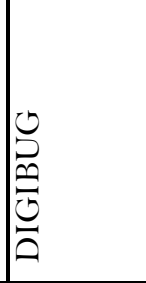 & 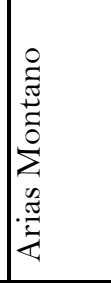 & 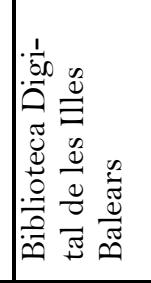 & 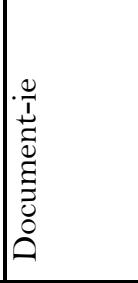 & 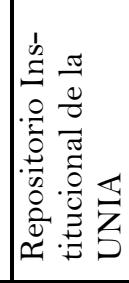 \\
\hline 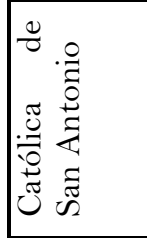 & 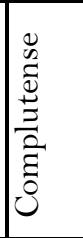 & $\vec{v}$ & 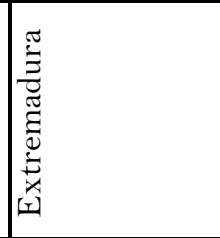 & 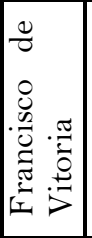 & 迆 & 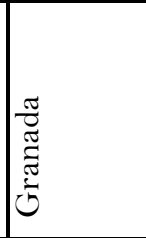 & $\begin{array}{l}\frac{\pi}{3} \\
\frac{3}{3}\end{array}$ & 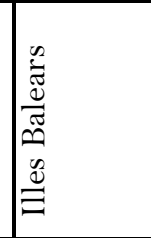 & 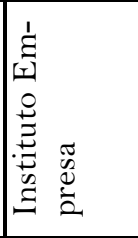 & 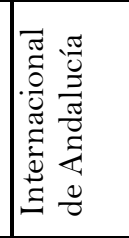 \\
\hline
\end{tabular}


MEI, II, Vol. 4, nº 6, pág. 88

\begin{tabular}{|c|c|c|c|c|c|c|c|c|c|}
\hline & & & & 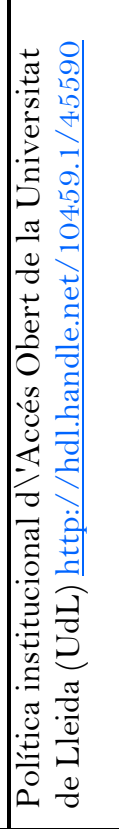 & 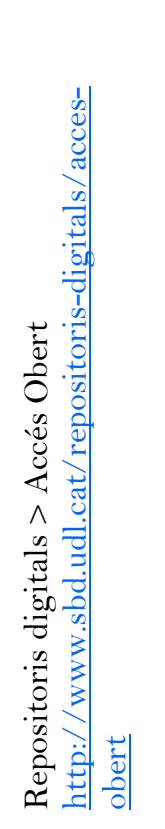 & 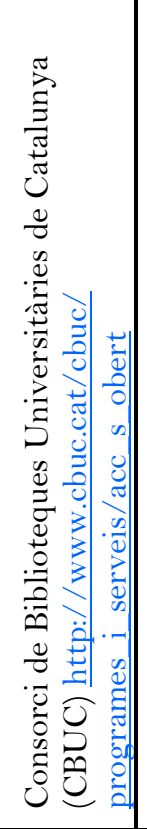 & & & 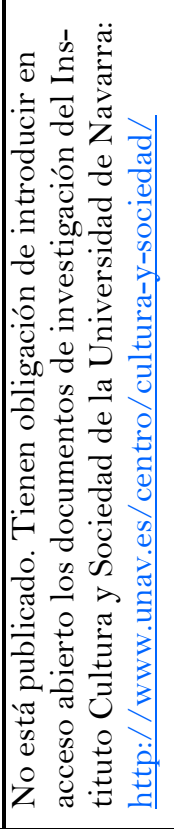 \\
\hline$\overbrace{z}$ & 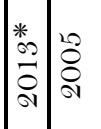 & \begin{tabular}{l|l}
0 \\
$a_{1}$ & $\mathbf{z}$
\end{tabular} & $\overrightarrow{\vec{a}}$ & \begin{tabular}{l}
0 \\
\multirow{8}{*}{} \\
\hdashline
\end{tabular} & & & 絭 & $\overrightarrow{\vec{े}}$ & $\stackrel{8}{z}$ \\
\hline $\mid$ & 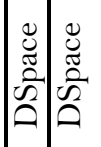 & 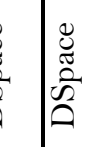 & 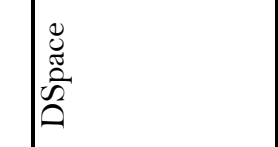 & $\mid$ & & & 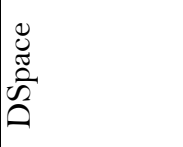 & 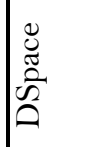 & 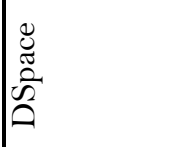 \\
\hline $\mid$ & 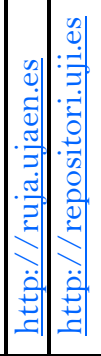 & 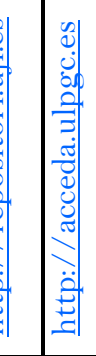 & (a) & 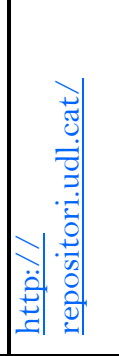 & & & | & : & 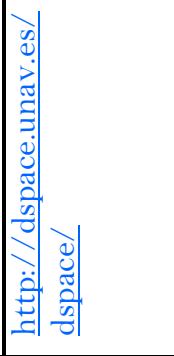 \\
\hline $\mid$ & 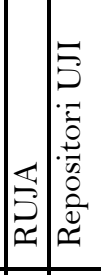 & 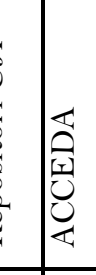 & 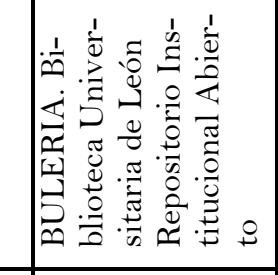 & 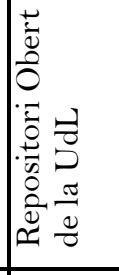 & & & 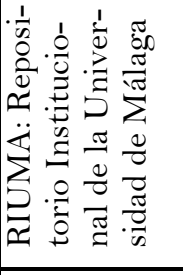 & 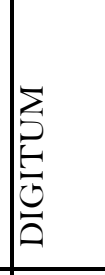 & 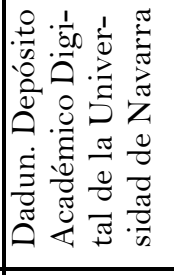 \\
\hline $\mid$ & 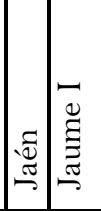 & 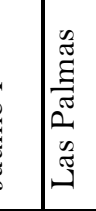 & . & ) & & & 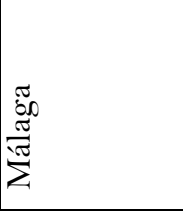 & 范 & 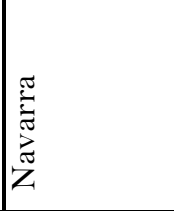 \\
\hline
\end{tabular}


MEI, II, Vol. 4, nº 6, pág. 89

\begin{tabular}{|c|c|c|c|c|c|c|c|c|}
\hline 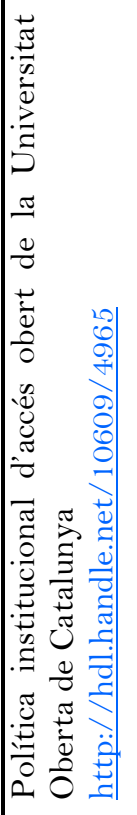 & & & 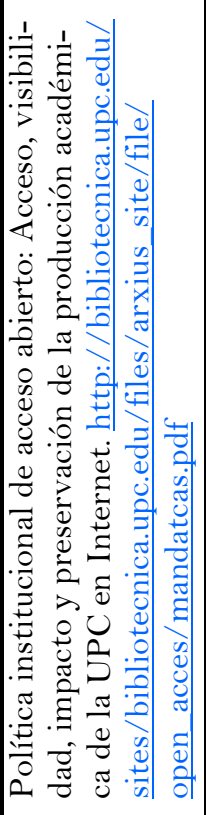 & 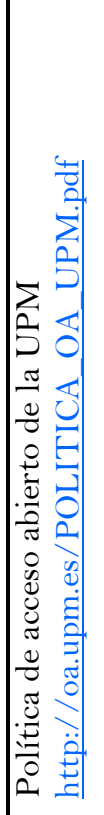 & 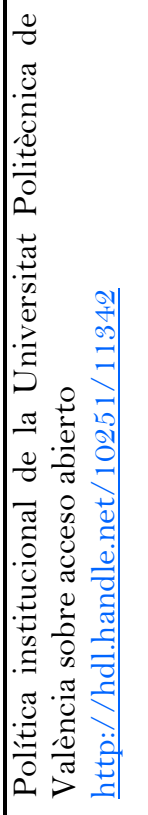 & 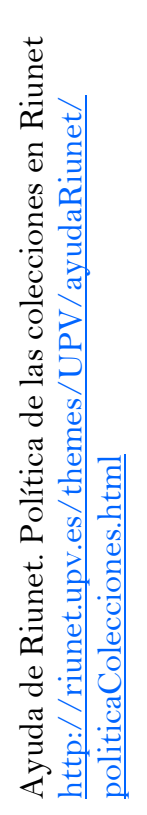 & 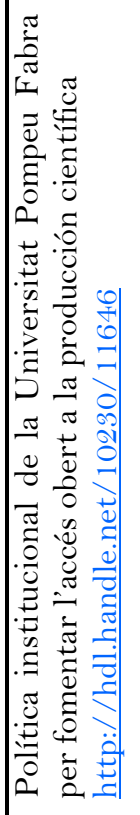 & \\
\hline 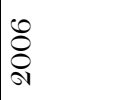 & 0 & 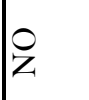 & 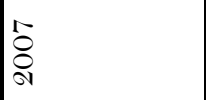 & \begin{tabular}{l}
0 \\
$\vdots$ \\
\hdashline
\end{tabular} & $\overrightarrow{\vec{D}}$ & & 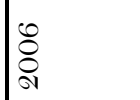 & $\hat{z}$ \\
\hline 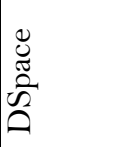 & 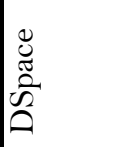 & 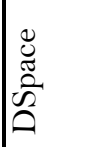 & 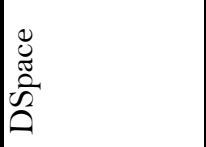 & 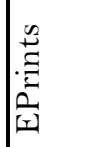 & 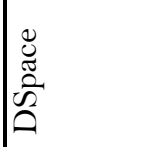 & & 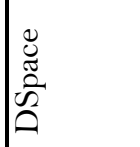 & 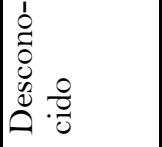 \\
\hline 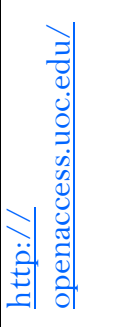 & 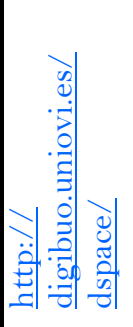 & 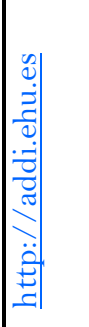 & 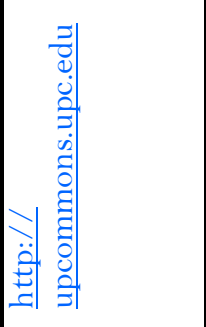 & 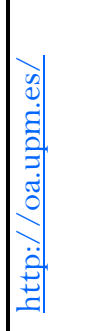 & 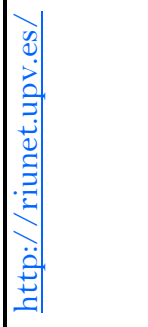 & & 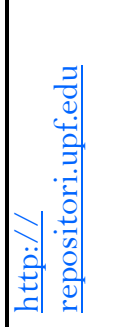 & 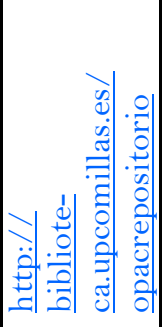 \\
\hline 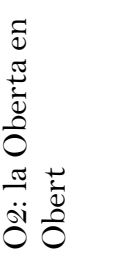 & 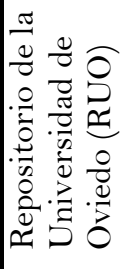 & $\overrightarrow{\hat{\widehat{C}}}$ & 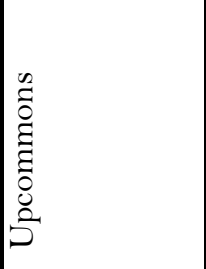 & 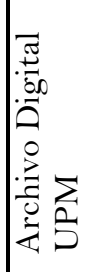 & 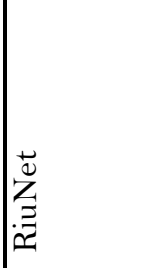 & & 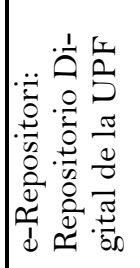 & 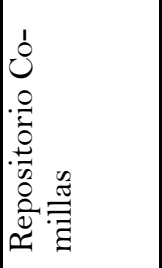 \\
\hline 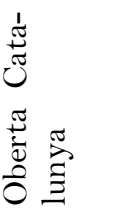 & $\frac{0}{\frac{8}{4}} \cdot \frac{0}{2}$ & 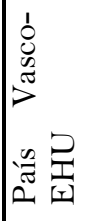 & 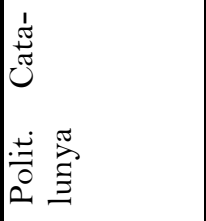 & 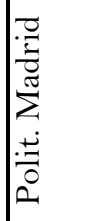 & 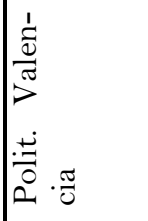 & & 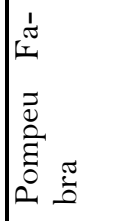 & 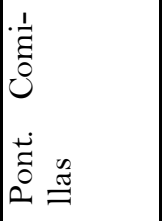 \\
\hline
\end{tabular}


MEI, II, Vol. 4, nº 6, pág. 90

\begin{tabular}{|c|c|c|c|c|c|c|c|c|c|c|}
\hline 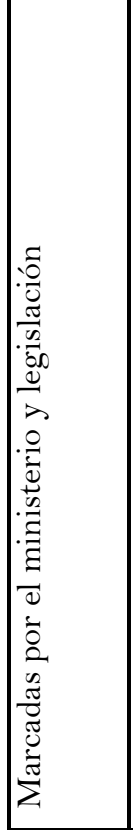 & 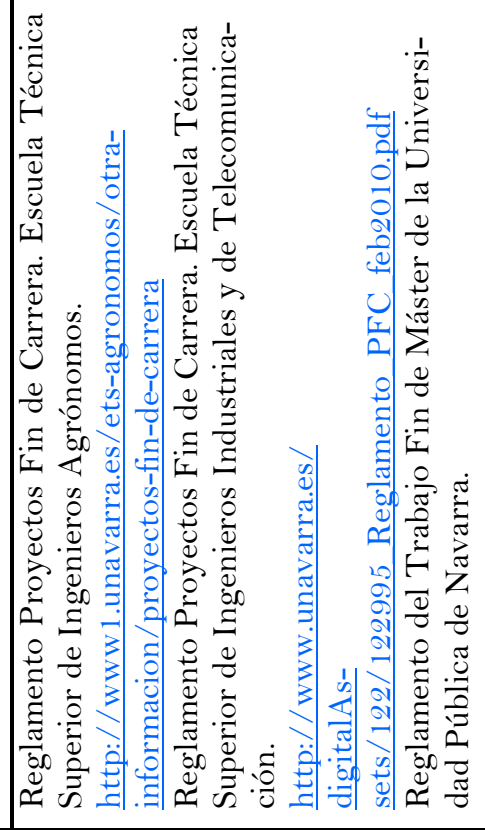 & 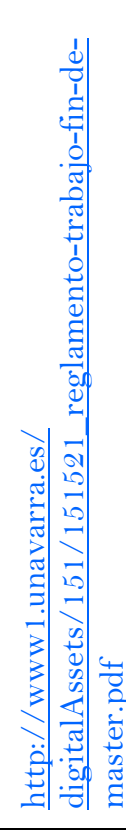 & 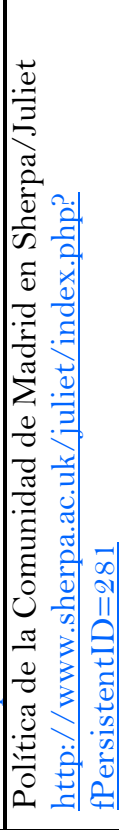 & 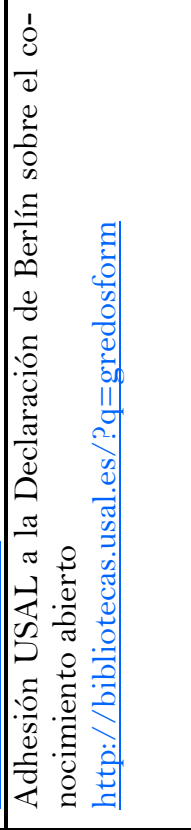 & & & & 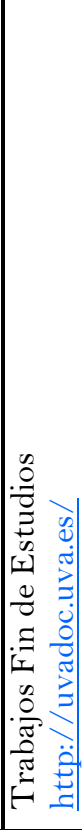 & & 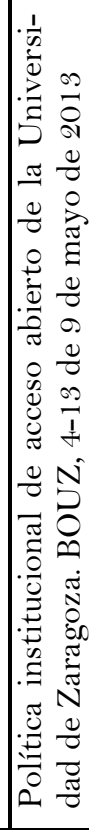 \\
\hline $\begin{array}{l}0 \\
z\end{array}$ & $\dot{z}$ & & 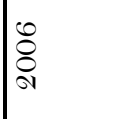 & 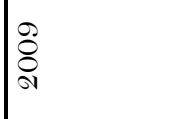 & $\left|\begin{array}{l}0 \\
8 \\
8 \\
-1\end{array}\right|$ & 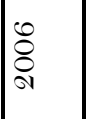 & 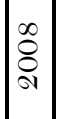 & $\begin{array}{l}\text { 类 } \\
\text { 永 } \\
\text { o1 }\end{array}$ & $\mid$\begin{tabular}{l}
0 \\
\multirow{0}{0}{} \\
जे
\end{tabular} & 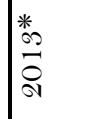 \\
\hline 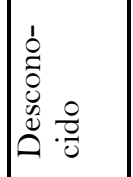 & 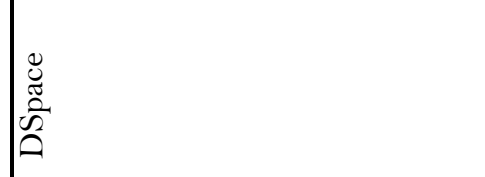 & & 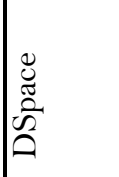 & 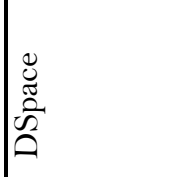 & 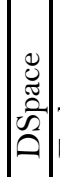 & 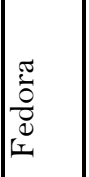 & 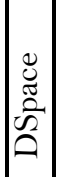 & 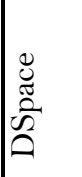 & 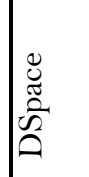 & 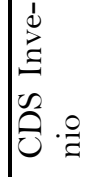 \\
\hline 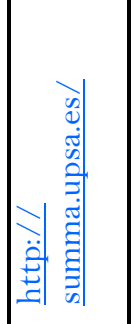 & 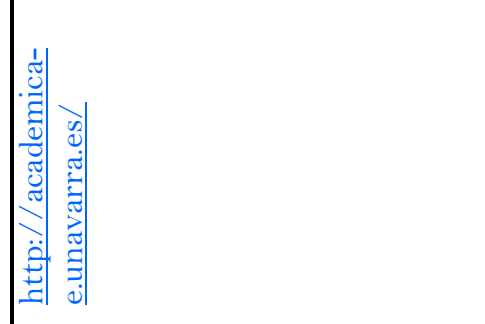 & & 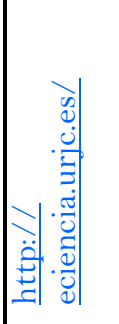 & 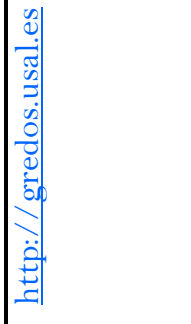 & 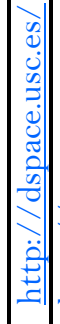 & 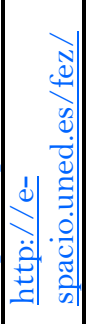 & 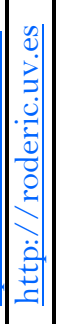 & 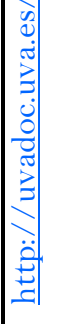 & 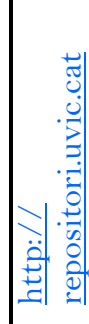 & + \\
\hline 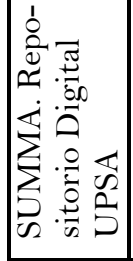 & 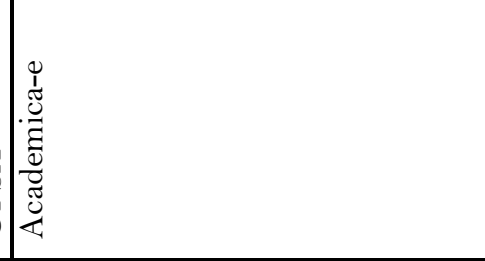 & & 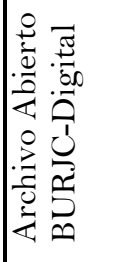 & 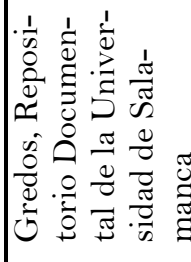 & 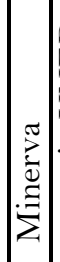 & 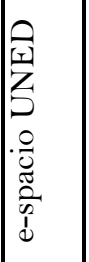 & 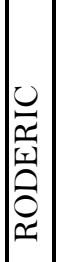 & 今ે & $\sum_{2}^{2}$ & 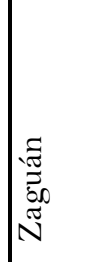 \\
\hline 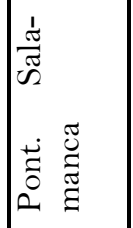 & 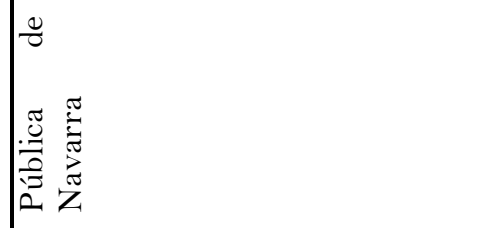 & & 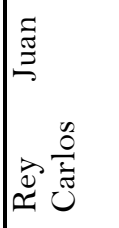 & $\begin{array}{l}\tilde{U} \\
\tilde{\Xi} \\
\tilde{\Xi} \\
\tilde{\Xi} \\
\tilde{\widetilde{J}} \\
\tilde{\Omega}\end{array}$ & $\left|\begin{array}{c}0 \\
. \\
. \\
\tilde{n} \\
\tilde{n}\end{array}\right|$ & 公 & 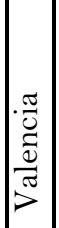 & 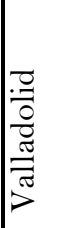 & 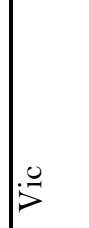 & 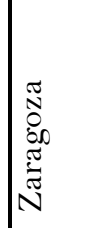 \\
\hline
\end{tabular}

* Firma posterior a la elaboración de la encuesta. Fuente: http://oa.mpg.de/lang/en-uk/berlin-prozess/ signatoren/ [Consulta: 26 Junio 2013] 